\title{
The ferrocenium/ferrocene couple: a versatile redox switch
}

\author{
Luigi Fabbrizzi ${ }^{1} \mathbb{D}$
}

Received: 9 July 2020 / Accepted: 12 September 2020 / Published online: 9 October 2020

(c) The Author(s) 2020

\begin{abstract}
Woodward and co-workers in 1952 characterised the unique structural features of ferrocene (the first sandwich compound), demonstrated its aromatic nature and observed that on treatment with mild oxidising agents (aqueous $\mathrm{Ag}_{2} \mathrm{SO}_{4}, p$-benzoquinone in organic solvents) the orange solution of ferrocene $(\mathrm{Fc})$ turned blue due to the formation of ferrocenium $\left(\mathrm{Fc}^{+}\right)$. A few months later, the one-electron $\mathrm{Fc} / \mathrm{Fc}^{+}$redox change was characterised polarographically by Page and Wilkinson with $E_{1 / 2}=0.31 \mathrm{~V}$ vs SCE $(0.56 \mathrm{~V}$ vs NHE) in ethanol/water 9:1. Since then ferrocene has become an icon of organometallic electrochemistry. Owing to the stability of its molecular framework, to the ease of functionalisation at the cyclopentadienyl rings and to the fast, reversible and kinetically uncomplicated $\mathrm{Fc} / \mathrm{Fc}^{+}$redox change, ferrocene has been used as a building block for the design of switchable functional systems. In this review, we will consider (1) electrochemical sensors for metal ions, anions and metal-anion pairs operating through the $\mathrm{Fc} / \mathrm{Fc}^{+}$redox change, (2) ferrocene-based redox switches of fluorescence and (3) cross-transport of electrons and anions through a liquid membrane mediated by lipophilic ferrocene derivatives.
\end{abstract}

\section{Graphic abstract}

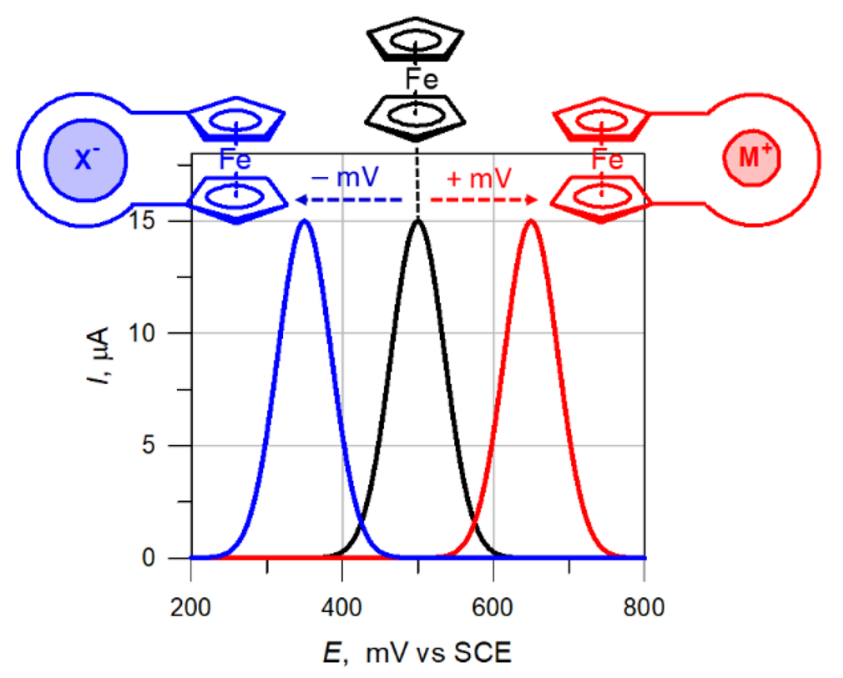

Keywords Ferrocene $\cdot$ Sandwich compounds $\cdot$ Redox switches $\cdot$ Electrochemical sensors $\cdot$ Liquid membranes

Luigi Fabbrizzi

luigi.fabbrizzi@unipv.it

1 Dipartimento di Chimica, Università di Pavia, 27100 Pavia, Italy

\section{The adventurous discovery of ferrocene}

The synthesis of ferrocene $\left(\left[\mathrm{Fe}\left(\eta^{5}-\mathrm{C}_{5} \mathrm{H}_{5}\right)_{2}\right]\right)$ and the elucidation of its structural and bonding properties in the early 1950s changed the way of thinking about coordination chemistry (the chemistry of the interaction of metal ions with non-metal donor atoms) and promoted the tumultuous 
development of organometallic chemistry (the chemistry of the metal-carbon interaction). As it often happens in chemistry, the synthesis of ferrocene was serendipitous. Peter Pauson (1925-2013), a British postdoctoral fellow at the Duquesne University in Pittsburgh, aged 26, was interested in verifying the possible aromatic nature of fulvalene (1) and attempted its synthesis according to the two following steps: (1) coupling of two molecules of cyclopentadienylmagnesium bromide to give the dihydro compound 2, (2) dehydrogenation (oxidation) of $\mathbf{2}$ with $\mathrm{FeCl}_{3}$ to give $\mathbf{1}$. To the great surprise of Pauson and of his student Tom Kealy, working for an MS degree, a yellow-orange crystalline precipitate formed, whose $\mathrm{C}$ and $\mathrm{H}$ microanalysis fitted the formula $\mathrm{C}_{10} \mathrm{H}_{10} \mathrm{Fe}$. The compound was extremely stable, melting at $173{ }^{\circ} \mathrm{C}$, sublimating under vacuum and being unaffected by boiling strong acids and strong alkalis. Pauson proposed the structural formula 3 (Fig. 1), which implied the formation of two intrinsically weak $\mathrm{Fe}-\mathrm{C} \sigma$ bonds. However, in order to account for the extreme stability of the new compound, Pauson suggested the contribution of the ionic resonance formula 4 , in which each cyclopentadienyl ring, owing to the acquisition of one negative charge, should present an aromatic character.

The paper by Pauson and Kealy ("A new type of organoiron compound") was submitted to Nature on 7 August 1951, and published in the 15 December 1951 issue [1]. Still in 1951, Samuel A. Miller, Director of Research with British Oxygen, London, with his co-workers John A. Tebboth and John F. Tremaine, isolated, again serendipitously, $\left[\mathrm{Fe}\left(\mathrm{C}_{5} \mathrm{H}_{5}\right)_{2}\right]$. In fact, on attempting the synthesis of amines from saturated and unsaturated hydrocarbons and nitrogen by using iron as a catalyst, they reacted cyclopentadiene and $\mathrm{N}_{2}$ at $300{ }^{\circ} \mathrm{C}$ at atmospheric pressure and obtained in good yield a yellow-orange solid, whose elemental analysis corresponded to $\left[\mathrm{Fe}\left(\mathrm{C}_{5} \mathrm{H}_{5}\right)_{2}\right]$. Miller and co-workers submitted the pertinent paper ("Cyclopentadienyliron") to J. Chem. Soc., which was received on 11 July 1951 [2]. This suggests that the research was carried out almost simultaneously in

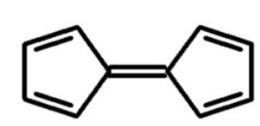

1

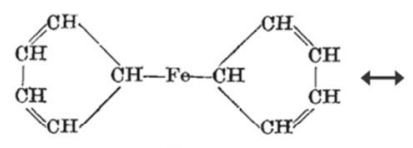

3
2

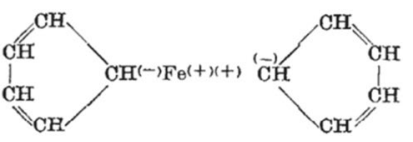

4

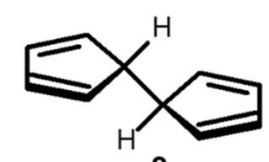

Fig. 1 Planned synthesis of fulvalene (1) through dehydrogenation of the dihydro derivative $\mathbf{2}$. The covalent formula of dicyclopentadienyliron proposed by Pauson (3); the ionic resonance formula disclosing the aromatic nature of each $\mathrm{C}_{5} \mathrm{H}_{5}$ ring (4). Formulae 3 and 4 reproduced from Pauson's paper [1]
Pittsburgh and in London and that the work was completed by the industrial researchers at least 1 month before Pauson and Kealy. However, the publishing procedure of $J$. Chem. Soc. was quite long (compared to Nature) and the article appeared on 24 March 1952. Miller's paper focused on the technical aspects of the synthesis and did not contain any speculation on bonding and structural features of [Fe $\left.\left(\mathrm{C}_{5} \mathrm{H}_{5}\right)_{2}\right]$. Simply, a formula analogous to 3 was reported in the article.

The issue of Nature containing Pauson's paper reached university libraries of Western countries during the first 2 weeks of January 1952. Robert B. Woodward (1917-1979), professor of organic chemistry at Harvard University, already an established star on the international chemistry scene, read the article and told his student Myron Rosenblum and his postdoctoral associate Mark Whiting to synthesize dicyclopentadienyl iron and to characterise its physical properties and its reactivity. Geoffrey Wilkinson (1921-1996), an English chemist, who had recently taken up an assistant professorship of inorganic chemistry at Harvard, joined the team. After a couple of months, they submitted a preliminary communication to J. Am. Chem. Soc. ("The structure of iron bis-cyclopentadienyl"), received on 24 March 1952, which was published on 2 April 1952 [3]. The authors suggested a structural arrangement in which iron is in-between two parallel cyclopentadienyl rings, as illustrated by the beautiful drawing in Fig. 2 (formulae a and $\mathbf{b}$ ).

Such a genial intuition was supported by a single experimental observation: the infrared absorption spectrum contained a single sharp band at $3050 \mathrm{~cm}^{-1}$, which indicated the presence in the compound of $\mathrm{C}-\mathrm{H}$ bonds of only one type. In addition, further pieces of information were provided: $\left[\mathrm{Fe}\left(\mathrm{C}_{5} \mathrm{H}_{5}\right)_{2}\right]$ was diamagnetic, apolar, it could be easily oxidised by dioxygen in acidic solution, by halogens and by $\mathrm{FeCl}_{3}$, to give a blue solution of $\left[\mathrm{Fe}\left(\mathrm{C}_{5} \mathrm{H}_{5}\right)_{2}\right]^{+}$, which was isolated as a solid, $\left[\mathrm{Fe}\left(\mathrm{C}_{5} \mathrm{H}_{5}\right)_{2}\right] \mathrm{GaCl}_{4}$, paramagnetic because of a single electron. The authors preliminarily hypothesised the formation of covalent interactions between the iron atom and the cyclopentadienyl rings, and observed that the number of electrons available for iron to carbon binding is 18 ( $5 \pi$ electrons for each cyclopentadienyl unit, plus the 8 electrons of iron), like the inert gas krypton. Finally, they emphasised the analogy of the $\left[\mathrm{Fe}\left(\mathrm{C}_{5} \mathrm{H}_{5}\right)_{2}\right]$ (diamagnetic)/ $\left[\mathrm{Fe}\left(\mathrm{C}_{5} \mathrm{H}_{5}\right)_{2}\right]^{+}$(paramagnetic) redox couple and of the ferrocyanide (diamagnetic)/ferricyanide (paramagnetic) redox couple. In a subsequent communication to J. Am. Chem. Soc. ("A new aromatic system", received on 2 June 1952) [5], Woodward and his research associates (Wilkinson had left the team) demonstrated the aromatic nature of $\left[\mathrm{Fe}\left(\mathrm{C}_{5} \mathrm{H}_{5}\right)_{2}\right]$. In particular, when $\left[\mathrm{Fe}\left(\mathrm{C}_{5} \mathrm{H}_{5}\right)_{2}\right]$ in $\mathrm{CS}_{2}$ was treated with acetyl chloride in the presence of $\mathrm{AlCl}_{3}$, it was very smoothly converted to a beautifully crystalline red diacetyl 


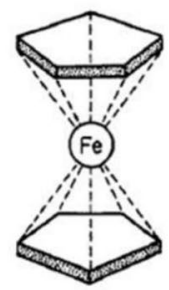

a

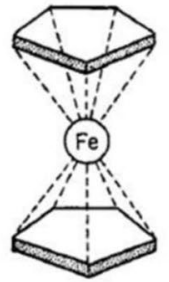

b

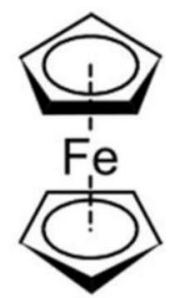

C

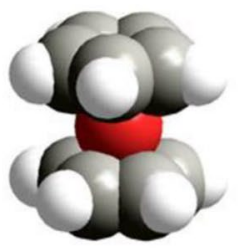

d

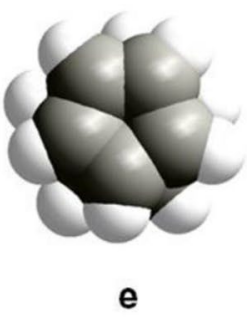

Fig. 2 Structure of dicyclopentadienyliron (ferrocene): $\mathbf{a}$ and $\mathbf{b}$ original drawings by Woodward et al., illustrating the two possible conformers: staggered (a) and eclipsed (b) [3]; current graphical repre- sentation of ferrocene (c); X-ray structure of ferrocene, overlapping spheres rendering, lateral view (d), top view (e) [4] derivative $\left[\mathrm{Fe}\left(\mathrm{C}_{5} \mathrm{H}_{4}\left(\mathrm{COCH}_{3}\right)\right)_{2}\right]$. Oxidation of the diacetyl derivative with hypoiodite gave the corresponding dicarboxylic acid, whose stepwise acidity constants in EtOH/ $\mathrm{H}_{2} \mathrm{O}$ $(2: 1, \mathrm{v} / \mathrm{v})\left(\mathrm{p} K_{\mathrm{a} 1}=6.51, \mathrm{p} K_{\mathrm{a} 2}=7.55\right)$ were comparable to the acidity constant of benzoic acid $\left(\mathrm{p} K_{\mathrm{a}}=6.57\right)$. In these circumstances, Woodward suggested for $\left[\mathrm{Fe}\left(\mathrm{C}_{5} \mathrm{H}_{5}\right)_{2}\right]$ the name ferrozene (crasis of the words ferrous and benzene). Whiting probably misunderstood the spelling and wrote in his notebook ferrocene (perhaps inspired by the other aromatic derivative anthracene), which was accepted and remained. Ferrocene is currently abbreviated to $\mathrm{Fc}$. $\left[\mathrm{Fe}\left(\mathrm{C}_{5} \mathrm{H}_{5}\right)_{2}\right]^{+}$was named by Woodward ferricinium [5], but it is today universally called ferrocenium (abbreviated to $\mathrm{Fc}^{+}$).

Dicyclopentadienyl iron aroused interest on the other side of the Atlantic, too. Ernest Otto Fischer (1918-2007), research assistant in the Institute of Inorganic Chemistry at the Technische Hochschule München, who had just finished the experimental work for his doctoral thesis, gave Reinhard Jira, a student, the task of carrying out a few practical syntheses drawn from chemical literature in order to complete his curriculum before the examination for the 'Diplomchemiker' degree. Among the varying syntheses, Fischer suggested that of dicyclopentadienyl iron, based on Pauson's recipe [1]. Jira did his job and obtained beautiful orange crystals, which were stable in air and additionally in an autoclave containing carbon monoxide at high temperature $\left(\mathrm{ca} .150^{\circ} \mathrm{C}\right.$ ) at $200 \mathrm{bar}$ (no formation of $\mathrm{Fe}(\mathrm{CO})_{5}$ ). The robustness of the compound led Fischer to the conclusion that probably the $6 \pi$ electron pairs of the two 'aromatic' rings of the cyclopentadienide anions would participate in the bonding to the central $\mathrm{Fe}^{\mathrm{II}}$ ion, while each negatively charged cyclopentadienyl ring was acting as a tridentate ligand and filled the iron(II) orbitals up to 18 electrons, the 'krypton configuration' (12 electrons from the two $\mathrm{C}_{5} \mathrm{H}_{5}{ }^{-}$units to be added to the 6 electrons of $\mathrm{Fe}^{\mathrm{II}}, 3 d^{6}$ ). Moreover, preliminary X-ray diffraction studies by Pfab, a colleague at the Technische Hochschule, showed that the $\left[\mathrm{Fe}\left(\mathrm{C}_{5} \mathrm{H}_{5}\right)_{2}\right]$ molecule was centrosymmetric, which led Fischer to propose a structure in which the $\mathrm{Fe}^{\mathrm{II}}$ ion was in-between two parallel cyclopentadienide rings. In a similar synthetic way, the very stable complex cation $\left[\mathrm{Co}\left(\mathrm{C}_{5} \mathrm{H}_{5}\right)\right]^{+}$ could be obtained, which was precipitated as a Reinecke salt, $\left[\mathrm{Co}\left(\mathrm{C}_{5} \mathrm{H}_{5}\right)\right]\left[\mathrm{Cr}(\mathrm{NCS})_{4}\left(\mathrm{NH}_{3}\right)_{2}\right]$. Like ferrocene, $\left[\mathrm{Co}\left(\mathrm{C}_{5} \mathrm{H}_{5}\right)_{2}\right]^{+}$ obeys to the 18 -electron rule ( 6 electrons from $\mathrm{Co}^{\mathrm{III}}, 3 d^{6}$, plus 12 electrons from the two $\mathrm{C}_{5} \mathrm{H}_{5}{ }^{-}$units). Both $\mathrm{Fe}^{\mathrm{II}}$ and $\mathrm{Co}^{\mathrm{III}}$ were supposed to hybridise their $3 d_{x 2-y 2}, 3 d_{z 2}, 4 s, 4 p_{x}$, $4 p_{y}$ and $4 p_{z}$ to give six octahedrally arranged $d^{2} s p^{3}$ hybrid orbitals, able to receive the $12 \pi$ electrons from the two staggered $\mathrm{C}_{5} \mathrm{H}_{5}{ }^{-}$units. The publication of the communication to J. Am. Chem. Soc. by Wilkinson and Woodward urged Fischer to submit his results to Zeitschrift für Naturforschung on 20 June 1952, ("Cyclopentadien-Metallkomplexe, ein neuer Typ metallorganischer Verbindungen") [6].

The comprehensible skepticism of the chemical community disappeared after Eiland and Pepinsky [7] and Dunitz [8] independently proved by X-ray crystallography that the unorthodox structure proposed by Woodward/Wilkinson and Fischer was correct (see Fig. $2 \mathrm{~d}$ and e). The theoretician Orgel, co-author of Dunitz's paper, used the molecular orbital (MO) theory to explain the bonding in ferrocene [8]. In particular, the mixing of metal and cyclopentadienyl orbitals imparts a strong covalent character to the bond, while delocalisation of electrons from $d_{x 2-y 2}$ and $d_{x y}$ orbitals of iron into empty $\pi$ antibonding orbitals of cyclopentadienyl makes the two rings acquire a partial negative charge. The title of the paper ("Bis-cyclopentadienyl iron: a molecular sandwich") introduced a new term currently used to describe chemical compounds featuring a metal bound by haptic covalent bonds to two arene ligands.

Wilkinson continued independently his research in the field and submitted to Journal of the American Chemical Society a series of three communications published as consecutive papers in the 5 December 1952 issue of the journal [9-11]. In the following years, he and his Harvard group rapidly extended the concept of the "sandwich" structure with a stream of seminal papers, laying a large part of the basis of transition metal organometallic chemistry. In spite of these brilliant results, Wilkinson failed to get tenure and left Harvard in January and moved to London, where he was 
appointed as a professor of inorganic chemistry at Imperial College. Among other achievements, he prepared the rhodium phosphine complex, later to become known as Wilkinson's catalyst, which became a major factor in organic synthesis and development work for important pharmaceuticals. Fischer followed his initial accomplishment with the discovery of dibenzenechromium, consisting of two sixsided carbon rings sandwiching a chromium atom. Over the years, Fischer's group in Münich produced a host of new organometallic complexes, included the first compounds with metal-carbon double bonds ('carbenes' in 1964) and metal-carbon triple bonds ('carbynes', 1973). Wilkinson and Fischer shared the Nobel Prize in Chemistry in 1973 "for their pioneering work, performed independently, on the chemistry of the organometallic, so called sandwich compounds". What about Woodward? Woodward published his third and last paper on ferrocene in 1958 [12]. Apparently, ferrocene was only a brilliant excursion in organometallic chemistry, in a lifelong activity dedicated to synthesis and characterisation of complex natural substances, from cholesterol, to strychnine, to cephalosporin, to vitamin $B_{12}$ (a gigantic enterprise). In 1965 he was awarded with the Nobel Prize in Chemistry "for his outstanding achievements in the art of organic synthesis". He was not happy for being excluded from the Nobel Prize for Chemistry for sandwich complexes, and sent a bitter letter to the Nobel Committee for Chemistry: "The notice in The Times of London (October 24; p. 5) of the award of this year's Nobel Prize in Chemistry leaves me no choice but to let you know, most respectfully, that you have inadvertently, I am sure, committed a grave injustice". During these years, he was developing, in collaboration with Roald Hoffmann, the theory of the conservation of orbital symmetry, a revolutionary work that gave MO theory a practical role in organic chemistry which hitherto it had lacked [13]. In 1981, Hoffmann was awarded with the Nobel Prize in Chemistry, jointly with Kenichi Fukui, "for their theories, developed independently, concerning the course of chemical reactions." This time, too, Woodward was excluded from a highly deserved award, but it happened for an unquestionable reason. He had died from a stroke during his sleep in 1979, aged 62, and Nobel Prizes are not awarded posthumously. Hence, he missed his second (or third?) Nobel Prize.

\section{Electrochemistry of ferrocene/ferrocenium redox change}

The first electrochemical investigation on the redox chemistry of ferrocene was carried out by John Page, a graduate student at Harvard, whom Wilkinson had asked to carry out a polarographic study on ferrocene [11]. Page studied the behaviour at the dropping mercury electrode of a ferrocene solution $90 \%$ in EtOH and $10 \%$ in $0.1 \mathrm{M} \mathrm{HClO}_{4}$, which had been made $0.1 \mathrm{M}$ in $\mathrm{NaClO}_{4}$, and determined an $E_{1 / 2}$ of $0.31 \mathrm{~V}$ vs SCE. The one-electron nature of the oxidation was confirmed by the measured $0.91 \mathrm{~F} / \mathrm{eqv}$ released during controlled potential electrolysis at a mercury pool electrode. The first studies on the oxidation of ferrocene in non-aqueous solutions (e.g. MeCN) were carried out in 1959 by Kuwana, Bublitz and Hoh, all graduate students at the University of Kansas, who used solid electrodes (usually platinum) [14]. The use of solid electrodes circumvented the problem of the oxidation of mercury and expanded the positive window of potential, thus facilitating the study of anodic reactions. By using the then-popular technique of chronopotentiometry, they observed that ferrocene oxidation was well behaved and reversible in acetonitrile $0.2 \mathrm{M} \mathrm{LiClO}_{4}$ at a Pt electrode, with $E_{1 / 2}=0.31 \mathrm{~V}$ vs SCE.

Ferrocene and other metallocenes (i.e. analogues of ferrocene in which the iron atom has been replaced by another transition metal) favoured the development of the flourishing area of organometallic electrochemistry, which was accompanied by fundamental advances in the theory, methodology and instrumentation of electroanalytical chemistry [15]. In particular, commercial availability of high-performance three-electrode potentiostats and multipurpose instruments made it possible for scientists outside of the tribe of pure electrochemists to use of a variety of techniques such as linear sweep voltammetry, cyclic voltammetry (CV), differential pulse voltammetry DPV) and bulk electrolysis.

$\mathrm{Fc} / \mathrm{Fc}^{+}$became the iconic redox couple of organometallic electrochemistry for two main reasons: (1) the $\mathrm{Fc} / \mathrm{Fc}^{+}$ self-exchange reaction is fast and kinetically uncomplicated and (2) its rate does not vary with the solvent. The former point arises because the sandwich geometry is maintained upon one-electron removal, both $\mathrm{Fc}$ and $\mathrm{Fc}^{+}$are low-spin, and only a slight elongation of the $\mathrm{Fe}-\mathrm{C}$ bonding distances takes place (the electron is removed from an essentially nonbonding molecular orbital, of predominant $d_{x z}$ character). The second point arises because redox change involves a moderate variation of the electric charge of the metal and, in addition, the iron is buried between the cyclopentadienyl rings, which nearly touch and thus shield the iron from solvent molecules. The heterogeneous electron transfer at the solid electrode is equally fast and not complicated by homogeneous reactions, and is electrochemically reversible (i.e. the coefficient of the electron transfer is higher than the coefficient of the mass transport). Thus, in the CV profile, the ratio of the current intensities of the peaks of the forward and of the reverse scan $\left(i_{\mathrm{p}(\mathrm{f})} / i_{\mathrm{p}(\mathrm{r})}\right)$ is the unity, and the peak-to-peak separation, $\Delta E_{\mathrm{p}}$, at $25^{\circ} \mathrm{C}$, is very close to the canonical value, $59 \mathrm{mV}$. The average of the potentials of the two peaks gives the $E_{1 / 2}$ value, according to Eq. (1). When the diffusion coefficients of the oxidised and reduced species are very similar, the half-wave potential provides a 
good approximation to the formal potential, that is the thermodynamically significant quantity.

$E_{1 / 2}=1 / 2\left(E_{\mathrm{p}(\mathrm{f})}+E_{\mathrm{p}(\mathrm{r})}\right)$

The choice of a universal and reliable reference electrode was one of the problems that organometallic electrochemistry, typically carried out in non-aqueous solvents, had to face at its beginning. The classical reference electrode used in water, SCE, included the unknown liquid junction potentials between the solution and the reference electrode, which vary with the solvent and with the geometry of the cell. To circumvent the problem it was suggested that ferrocene should be used as an internal standard for electrochemical studies in organic solvents and that the reduction potentials of any redox change in a given medium should be reported vs the $\mathrm{Fc}^{+} / \mathrm{Fc}$ couple $[16,17]$. After the wave attributed to the compound of interest has been identified, a roughly equimolar amount of ferrocene is added to the cell, the electrochemical experiment is repeated and the $E_{1 / 2}$ of the envisaged wave(s) can be directly compared to the $E_{1 / 2}$ of the $\mathrm{Fc}^{+} / \mathrm{Fc}$ couple. A platinum wire is typically used as a pseudo-reference electrode. Figure 3 shows a $\mathrm{CV}$ profile obtained at a platinum working electrode for an $\mathrm{MeCN}$ solution containing ferrocene and $\left[\mathrm{Ni}^{\mathrm{II}}\right.$ (cyclam) $]\left(\mathrm{ClO}_{4}\right)_{2}$ (supporting electrolyte $\left.\mathrm{Bu}_{4} \mathrm{NBF}_{4}, T=25^{\circ} \mathrm{C}\right)$. $\left[\mathrm{Ni}^{\mathrm{II}}(\text { cyclam })\right]^{2+}$ undergoes reversible oxidation to $\left[\mathrm{Ni}^{\mathrm{III}} \text { (cyclam) }\right]^{3+}$ and reversible reduction to $\left[\mathrm{Ni}^{\mathrm{I}}(\text { cyclam })\right]^{+}[18]$.

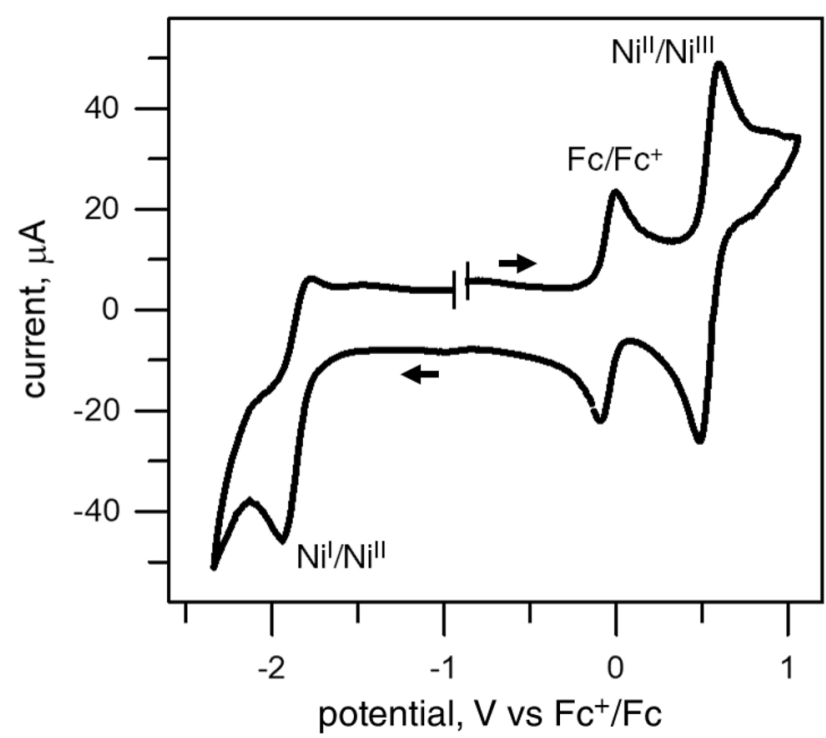

Fig. $3 \mathrm{CV}$ profile obtained at a Pt microsphere working electrode for an $\mathrm{MeCN}$ solution made $0.1 \mathrm{M}$ in $\mathrm{Bu}_{4} \mathrm{NBF}_{4}$, at $T=25{ }^{\circ} \mathrm{C}$, and containing $\left[\mathrm{Ni}^{\mathrm{II}}(\right.$ cyclam $\left.)\right]\left(\mathrm{ClO}_{4}\right)_{2}$, and ferrocene as an internal reference. Potential scan rate $200 \mathrm{mV} \mathrm{s}^{-1}$. The counter electrode was a Pt foil, the pseudo-reference electrode a Pt wire [18]
In 1984, a distinguished IUPAC commission recommended that the couple $\mathrm{Fc}^{+} / \mathrm{Fc}$ should be employed as a redox reference system in non-aqueous solvents [19]. Notice that the expression "redox reference system" is semantically different from the expression "reference electrode", which refers to an electrode with a known, invariant, electrode potential (e.g. SCE). Indeed, the choice of ferrocene as an internal standard is adequate when $E_{1 / 2}$ values are compared within the same solvent containing the same background electrolyte. Change of the medium implies a variation of the interactions of $\mathrm{Fc}$ and $\mathrm{Fc}^{+}$with the environment, which include solvation effects and the formation of $\mathrm{Fc}^{+} . . . \mathrm{X}^{-}$ion pairs, where $\mathrm{X}^{-}$is the anion of the supporting electrolyte. In order to minimise such solute-solvent interactions, decamethylferrocene, $\mathrm{Me}_{10} \mathrm{Fc}(5)$ was proposed as a more effective solvent-independent internal standard [20]. In particular, the ten methyl substituents were expected to protect the iron centre from any substrate present in solution and to shield the electrostatic interactions with anions. Indeed, X-ray studies on $\mathrm{Me}_{10} \mathrm{Fc}$ showed that the contacts between the facing methyl groups of the two rings are within van der Waals distances [21], thus enclosing $\mathrm{Fe}$ in a rigid shell (see the space-filling rendering of the crystal structure of $\mathrm{Me}_{10} \mathrm{Fc}(\mathbf{a})$ compared to Fc (b) in Fig. 4.

From a practical point of view, the only significant difference is that the potential of the $\mathrm{Me}_{10} \mathrm{Fc}^{+} / \mathrm{Me}_{10} \mathrm{Fc}$ couple is shifted by ca $0.5 \mathrm{~V}$ toward negative values. This has to be ascribed to the electron-donating effect of the ten methyl groups, which pushes electron density toward the metal, thus favouring the electron removal from the neutral form by the electrode and disfavouring the electron uptake by the oxidised form from the electrode. This makes the $\mathrm{Me}_{10} \mathrm{Fc}^{+} /$ $\mathrm{Me}_{10} \mathrm{Fc}$ couple the ideal internal reference couple for easily oxidised solvents, such as $N$-methylaniline and $N, N$ dimethylaniline, whereas no response of the $\mathrm{Fc}^{+} / \mathrm{Fc}$ couple is observed within their potential window. Moreover, the $\mathrm{Me}_{10} \mathrm{Fc}^{+} / \mathrm{Me}_{10} \mathrm{Fc}$ redox couple allows the use of the easily oxidised mercury working electrode, thus extending the window of voltammetric investigation toward more negative potentials [20]. In spite of these benefits, ferrocene remains the preferred internal reference for electrochemical studies

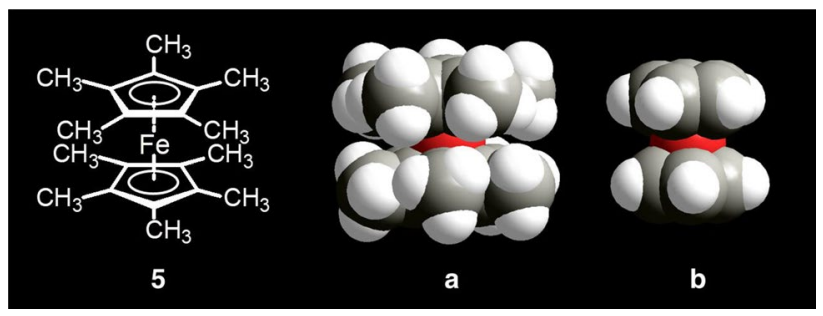

Fig. 4 Crystal structure of $\mathrm{Me}_{10} \mathrm{Fc}$ (5) [21], represented with a spacefilling rendering (a), compared to that of ferrocene (b) 
in non-aqueous media. The reason is that $1 \mathrm{~g}$ of decamethylferrocene costs US\$90, whereas with US\$89 you can buy $500 \mathrm{~g}$ of plain ferrocene (Strem Chemicals [22]). More specifically, decamethylferrocene has been explored as a redox probe to study transfer of ions and to measure the Gibbs energy of ion transfer across the interface of two hardly miscible liquids [23-26].

A final comment on the naming of the oxidised form of ferrocene: it was baptised ferricinium by its discoverers, but ferrocenium took over through the years. Gritzner and Kuta, in the IUPAC report on internal standard electrodes in non-aqueous solvents [19], used the name ferricenium. They probably considered that the ending "ium" in substitutive nomenclature refers to a compound which results from the addition of a proton to a neutral parent compound and that in strong acidic acid media, ferrocene is protonated to $\left[\mathrm{Fe}\left(\eta^{5}\right.\right.$ $\left.\left.\mathrm{C}_{5} \mathrm{H}_{5}\right)_{2} \mathrm{H}\right]^{+}$, a species in which a hydrogen atom is bound to the metal centre [27], and which could be rightfully called ferrocenium. On the other hand, if ferrocene results from the crasis of 'ferrous benzene', ferricenium may allude to the 'ferric' oxidation state of iron. The name 'ferrocinium' has also appeared in the literature (e.g. in ref. [16]), just to complete all the possible combinations.

\section{Redox switches: metaphors from the electrician and from the railroader}

"Switch" is one of the most frequently used terms that chemistry has borrowed from everyday language, in its two main senses: (i) a device for changing the connections in an electrical circuit; (ii) a device made by two movable rails and designed to turn a locomotive or train from one track to another. Redox switches of fluorescence apply well to meaning (i). A redox switch of fluorescence is a system consisting in two components: a light-emitting subunit and a control subunit [28]. The control subunit is a redox couple of which one form (e.g. the oxidised one) quenches the proximate fluorophore (state OFF) and the other form (e.g. the reduced one) does not (state ON), or vice versa. The first example of a redox switch of fluorescence based on a one-electron transfer process (6) is pictorially illustrated in Fig. 5 [29].

The light-emitting fragment (the bulb) is an anthracenoic ester fragment. The alkyl anthracenoate subunit, when excited at $375 \mathrm{~nm}$ (the lowest energy vibronic band of anthracene), emits an azure fluorescence, corresponding to a structureless emission band centred at $460 \mathrm{~nm}$ and associated with a charge transfer excited state $* A n_{\mathrm{CT}}$. The control unit in system 6 (the switch) is a copper complex of the macrocycle thiacyclam. When the copper centre is in the +2 oxidation state, an eT process takes place from $* \mathrm{An}_{\mathrm{CT}}$ to $\mathrm{Cu}^{\mathrm{II}}$, which quenches fluorescence (emission OFF). If the $\left[\mathrm{Cu}^{\mathrm{II}} \text { (thiacyclam) }\right]^{2+}$ fragment is reduced to the +1 oxidation state, the $\mathrm{Cu}^{\mathrm{I}}$-to- $* \mathrm{An}_{\mathrm{CT}}$ eT process becomes thermodynamically disfavoured and the azure fluorescence is revived.

Figure 6 shows the emission spectra in $\mathrm{MeCN}$ at $25^{\circ} \mathrm{C}$ of system 6 taken over the course of a controlled potential experiment: (1) before electrolysis the blue-green solution of the system containing $\mathrm{Cu}^{\mathrm{II}}$ is not fluorescent (eT operates); (2) the potential of the working electrode (a platinum gauze) is set at $200 \mathrm{mV}$ vs $\mathrm{SCE}, \mathrm{Cu}^{\mathrm{II}}$ is reduced to $\mathrm{Cu}^{\mathrm{I}}$, the solution decolorizes and a structureless emission band centred at $450 \mathrm{~nm}$ develops (eT does not operate); (3) the potential is set at $800 \mathrm{mV}$ vs SCE, oxidation to $\mathrm{Cu}^{\mathrm{II}}$ takes place, the blue-green colour of the solution is restored and fluorescence is quenched again (eT operates). Several oxidation-reduction cycles can be carried out without significant decomposition.

The first ferrocene-based redox switch of fluorescence ( 7 in Fig. 7) was reported by Molina and co-workers [30]. The switch (ferrocene) is connected to the bulb (pyrene) through an electron-permeable $\mathrm{C}=\mathrm{N}-\mathrm{N}=\mathrm{C}$ conjugated molecular wire. On irradiation at $350 \mathrm{~nm}$, the dyadic system 7 $\left(2.5 \times 10^{-5} \mathrm{M} \mathrm{MeCN}\right.$ solution) emits only weak fluorescence (see the spectrum of lowest intensity in Fig. 7). Quenching of fluorescence is due to the occurrence of an eT process
Fig. 5 A redox switch of fluorescence. The two-component system 6a is not fluorescent since the anthracene-based fluorophore is quenched by an electron transfer (eT) process from the excited fluorophore to the proximate $\mathrm{Cu}^{\mathrm{II}}$ ion; on one-electron reduction to $\mathbf{6 b}$ fluorescence is switched on as the eT process from $\mathrm{Cu}^{\mathrm{I}}$ to the excited fluorophore is not thermodynamically favoured and does not occur [29]

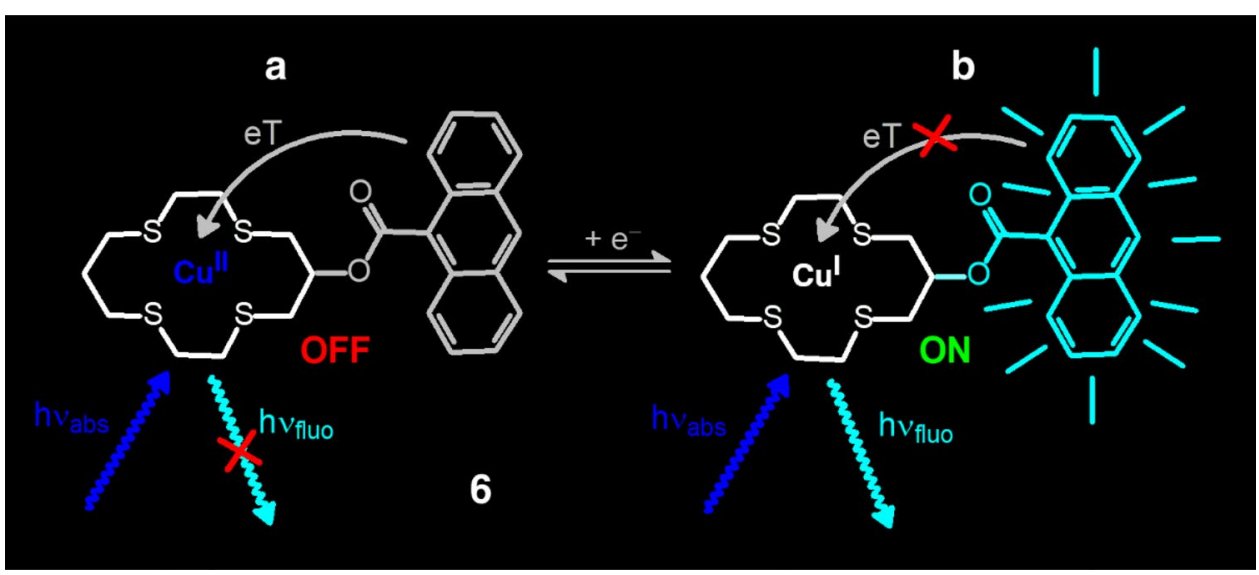




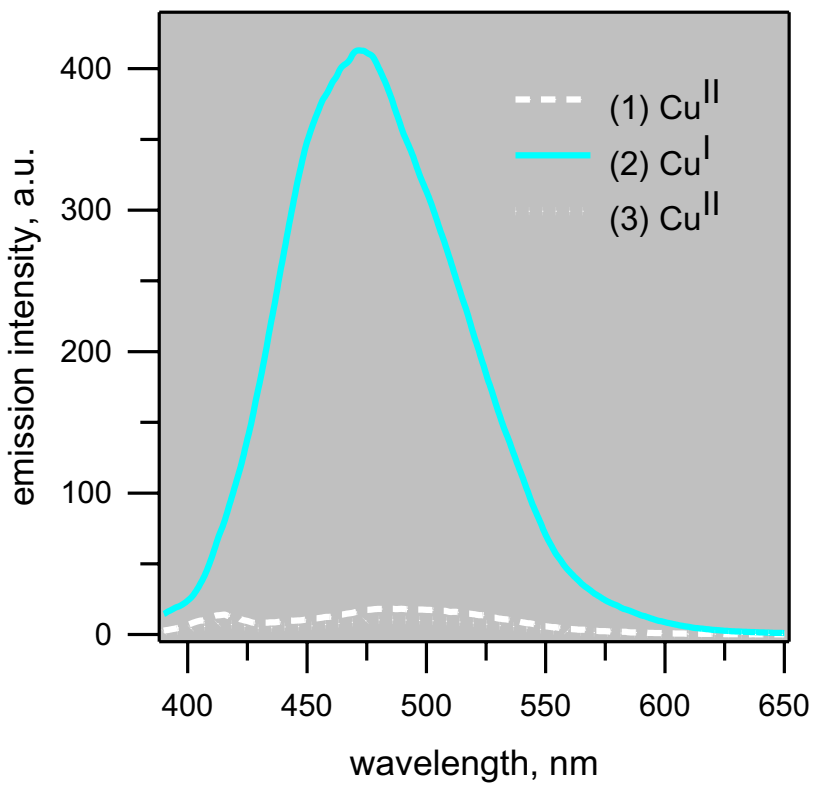

Fig. 6 Emission spectra of an MeCN solution of the two-component system 7, before and after controlled potential electrolysis; (1) before electrolysis (white dashed line, $\mathrm{Cu}^{\mathrm{II}}$ state) the solution does not fluoresce; (2) upon reduction to the $\mathrm{Cu}^{\mathrm{I}}$ state fluorescence is revived (azure solid line); (3) on anodic oxidation to $\mathrm{Cu}^{\mathrm{II}}$ (dotted white line) fluorescence is quenched [29]

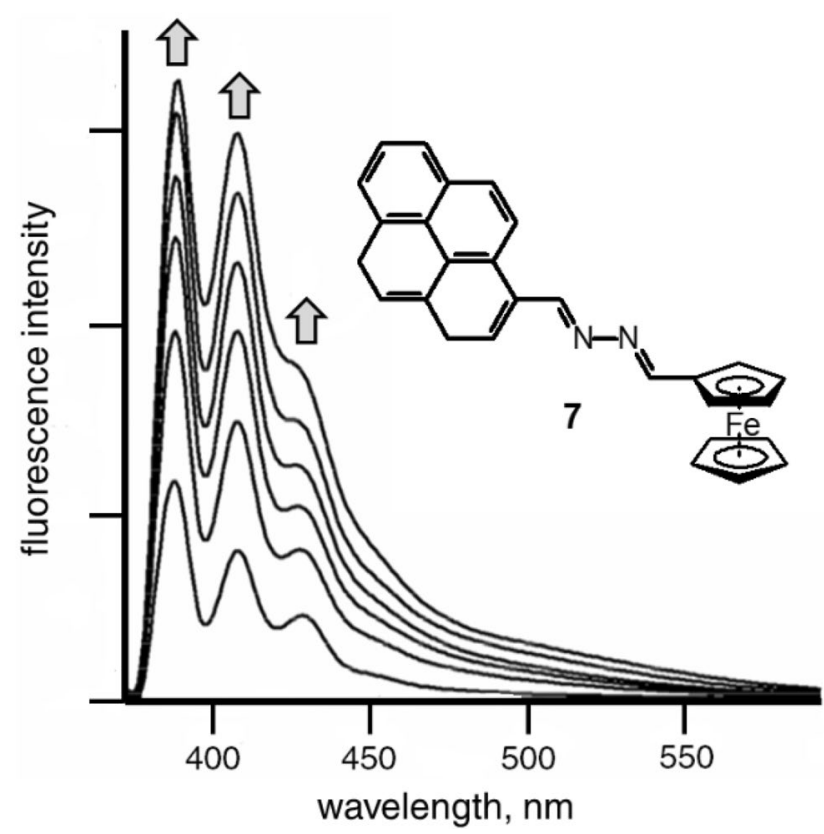

Fig. 7 Emission spectra of an $\mathrm{MeCN}$ solution $2.5 \times 10^{-5} \mathrm{M}$ of 7 $\left(\lambda_{\text {exc }}=350 \mathrm{~nm}\right)$ following the addition of aliquots of $\mathrm{Cu}\left(\mathrm{CF}_{3} \mathrm{SO}_{3}\right)_{2}$. Fluorescence revives as the oxidation of the $\mathrm{Fc}$ subunit to $\mathrm{Fc}^{+}$interrupts the electron transfer from $\mathrm{Fc}$ to the photo-excited state of pyrene, *Py [30] from the electron-rich ferrocene subunit to the excited state of the pyrene moiety *Py. On addition of $\mathrm{Cu}\left(\mathrm{CF}_{3} \mathrm{SO}_{3}\right)_{2}$, the thermal redox process $\left[\mathrm{Cu}^{\mathrm{II}}(\mathrm{MeCN})_{4}\right]^{2+}+\mathrm{Fc} \leftrightarrows$ $\left[\mathrm{Cu}^{\mathrm{I}}(\mathrm{MeCN})_{4}\right]^{+}+\mathrm{Fc}^{+}$takes place, which cancels any electron-donating tendency of the organometallic fragment, stops the electron transfer and revives the fluorescence. Full emission recovery is reached after the addition of 1 eqv of $\mathrm{Cu}\left(\mathrm{CF}_{3} \mathrm{SO}_{3}\right)_{2}$. On addition of ascorbic acid, $\mathrm{Fc}^{+}$is reduced to $\mathrm{Fc}$ and fluorescence emission is quenched again. Spectroelectrochemisty experiments carried out by setting alternatively the potential of the working platinum electrode at $0.9 \mathrm{~V}$ vs $\mathrm{Ag} / \mathrm{AgCl}$ (Fc-to- $\mathrm{Fc}^{+}$oxidation) and at $0.1 \mathrm{~V}$ vs $\mathrm{Ag} /$ $\mathrm{AgCl}\left(\mathrm{Fc}^{+}\right.$-to-Fc reduction) induced enhancement/decrease of fluorescence emission for several cycles, with complete recovery of the intensity, demonstrating the robustness of the dyadic system 7 .

Magri and co-workers reported an interesting system that contains two switches and one light bulb [31]. The threecomponent system is shown in Fig. 8.

One of the two switches is ferrocene, which behaves as an electron donor and transfers one electron to the proximate photo-excited anthracene fragment $*$ An, quenching its emission. On addition of a mild oxidising agent, $\mathrm{Fe}^{3+}$, ferrocene is oxidised to ferrocenium, which does not possess any donating tendency, and the Fc-to-*An eT process is stopped. The other switch is a tertiary amine fragment, also a good electron donor, which quenches *An through an eT process. Electron transfer is inhibited in the presence of strong acid which protonates the amine group. Therefore, fluorescence is revived only on addition of both $\mathrm{Fe}^{3+}$ and $\mathrm{H}^{+}$. The switch ferrocene is operated by a redox process, the switch tertiary amine is operated by an acid-base reaction.

Figure 9 shows the emission spectra taken on a $\mathrm{MeOH}$ solution containing (1) the three-component $\mathbf{8}$, form $\mathbf{a}$; (2) $\mathbf{8 a}+\mathrm{Fe}^{3+}\left(\right.$ from $\mathrm{Fe}_{2}\left(\mathrm{SO}_{4}\right)_{3} \cdot 5 \mathrm{H}_{2} \mathrm{O}$ ); (3) $\mathbf{8 a}+\mathrm{H}^{+}$(from $\mathrm{CF}_{3} \mathrm{SO}_{3} \mathrm{H}$ ); (4) $8 \mathrm{a}+\mathrm{Fe}^{3+}+\mathrm{H}^{+}$. Notice that only the simultaneous presence of $\mathrm{Fe}^{3+}$ and $\mathrm{H}^{+}$ensures a full revival of the anthracene emission spectrum.

System 8 rightfully belongs to the area of 'molecular logic', a topic invented in 1993 by A. P. de Silva, Queen's University, Belfast [32]. Molecular logic treats the design of simple molecular systems behaving as logic gates, and developed during the last three decades to a lively subdiscipline of supramolecular chemistry [33]. In this perspective, the considered system should be considered an AND logic gate, as indicated by its truth table in Fig. 8 .

To make things a bit more complicated, Magri and coworkers added to $\mathbf{8}$ a third switch, a benzo-crown-ether fragment, to give the four-component system 9, in Fig. 10 [34].

The 1,2-dimethoxybenzene fragment of the appended benzo-crown-ether is a powerful electron donor capable of quenching the fluorescent emission of the proximate anthracene moiety through a photo-induced electron 


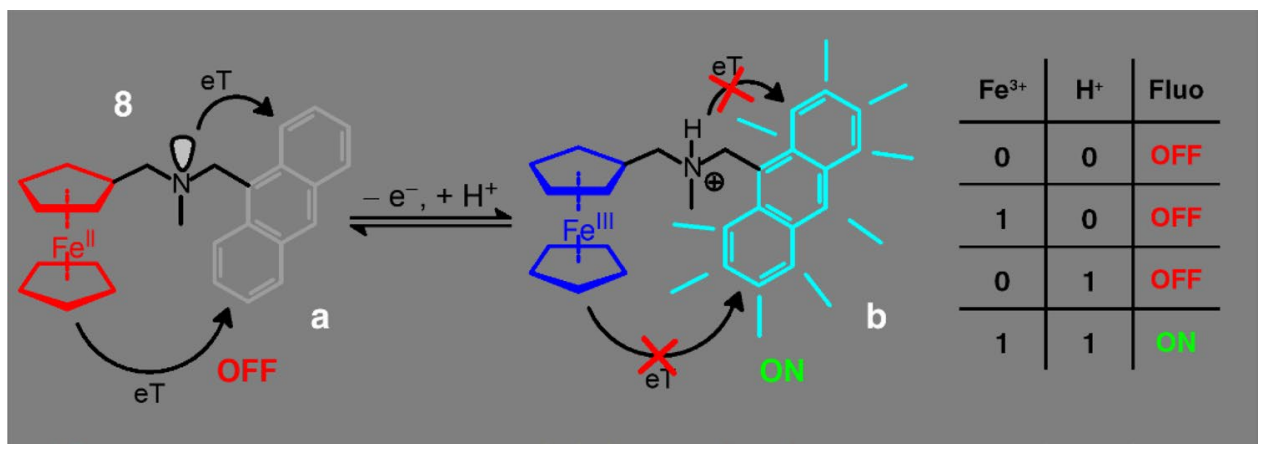

Fig. 8 A three-component switchable anthracene derivative (8) operated by two switches: ferrocene and a tertiary amine group [31]. Each of the two subunits transfers an electron to the photo-excited fluorophore, quenching emission. Oxidation of $\mathrm{Fc}_{\mathrm{c}} \mathrm{Fc}^{+}$and protonation of

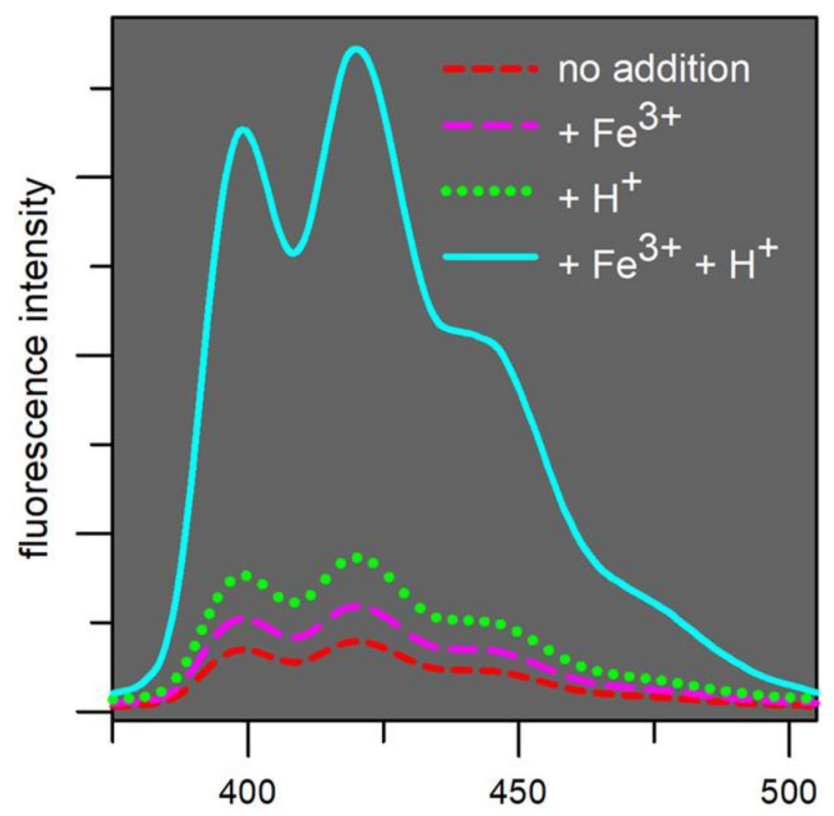

wavelength, $\mathrm{nm}$

Fig. 9 Fluorescence spectra of a $\mathrm{MeOH}$ solution $10^{-5} \mathrm{M}$ in $\mathbf{8}$, when excited at $365 \mathrm{~nm}$. An enhanced fluorescence signal is observed after oxidation of the ferrocene moiety with $\mathrm{Fe}^{3+}$ and protonation of the tertiary amine group [31]

transfer. The 15-membred crown ether shows a special affinity for $\mathrm{Na}^{+}$, due to the complementarity of the radius of the anion and the radius of ligand's circular cavity. On $\mathrm{Na}^{+}$complexation, the lone pairs of the two phenyl bound oxygen atoms become engaged in metal coordination and are no longer able to pump electrons to the benzene ring, whose donating tendencies are drastically reduced: the electron transfer to *An is prevented. Therefore, switching on of the anthracene fluorescence in system 9 requires the simultaneous addition of $\mathrm{Fe}^{3+}, \mathrm{H}^{+}$and $\mathrm{Na}^{+}$. We are again the amine group prevents the occurrence of the two eT processes and the form $\mathbf{b}$ displays the typical emission of anthracene. The system behaves like an AND logic gate as indicated by the truth table

in the presence of an AND logic gate, which this time is operated by three distinct inputs.

Following the aforementioned railway metaphor, the redox switch, depending on its oxidation state, turns the behaviour of a linked functional unit to one direction or to the other, quickly and reversibly. A simple example is provided by the ferrocene carboxylic acid $\mathbf{1 0}(\mathrm{Fc}-\mathrm{COOH})$ [35]. The acidic properties of $\mathbf{1 0}$ vary according to the oxidation state of the ferrocene subunit, as illustrated in the square scheme in Fig. 11.

Differential pulse voltammetry (DPV) experiments were carried out on $\mathrm{MeCN} / \mathrm{H}_{2} \mathrm{O}(4: 1, \mathrm{v} / \mathrm{v})$ solutions, whose $\mathrm{pH}$ was adjusted by appropriate buffers (pyridine, 2,6-dimethylpyridine, ethylenediamine). At each $\mathrm{pH}$, a single symmetric profile was observed, to be ascribed to the reversible $\mathrm{Fc}-$ to- $-\mathrm{Fc}^{+}$one-electron oxidation. On $\mathrm{pH}$ increase (from 2 to 10), the Gaussian profile shifted towards less positive potentials. The half-height width of each profile, $\delta_{1 / 2}$, was about $100 \mathrm{mV}$ (canonical value for a fully reversible process, at $25^{\circ} \mathrm{C}$, is $90 \mathrm{mV}$ ). Peak potential values $E_{1 / 2}$ are plotted vs pH in Fig. 12.

$E_{1 / 2}$ exhibits a constant value in more acidic solutions $(\mathrm{pH}<3)$, then decreases according to a reverse sigmoidal profile, and finally reaches a constant value in distinctly basic solutions $(\mathrm{pH}>9)$. Following the square scheme in Fig. 11, the $E_{1 / 2}$ value of each DPV profile $(\mathrm{mV})$ should depend upon the acidity according to Eq. (2) (potential expressed in $\mathrm{mV}$ )

$E_{1 / 2}=E^{\circ}(-\mathrm{COOH})-59.16 \log \frac{K_{\mathrm{a}}\left(\mathrm{Fc}^{+}\right)+\left[\mathrm{H}^{+}\right]}{K_{\mathrm{a}}(\mathrm{Fc})+\left[\mathrm{H}^{+}\right]}$

Non-linear fitting of Eq. (2) to the dependent variable $E_{1 / 2}$ and to the independent variable $\left[\mathrm{H}^{+}\right]$gave the following values for the investigated parameters: $E^{\circ}(-\mathrm{COOH})=528 \pm 1 \mathrm{mV} ; \mathrm{p} K_{\mathrm{a}}(\mathrm{Fc})=7.79+0.08$; $\mathrm{p} K_{\mathrm{a}}\left(\mathrm{Fc}^{+}\right)=4.54 \pm 0.04$. Equation (1) fits the data well, as 


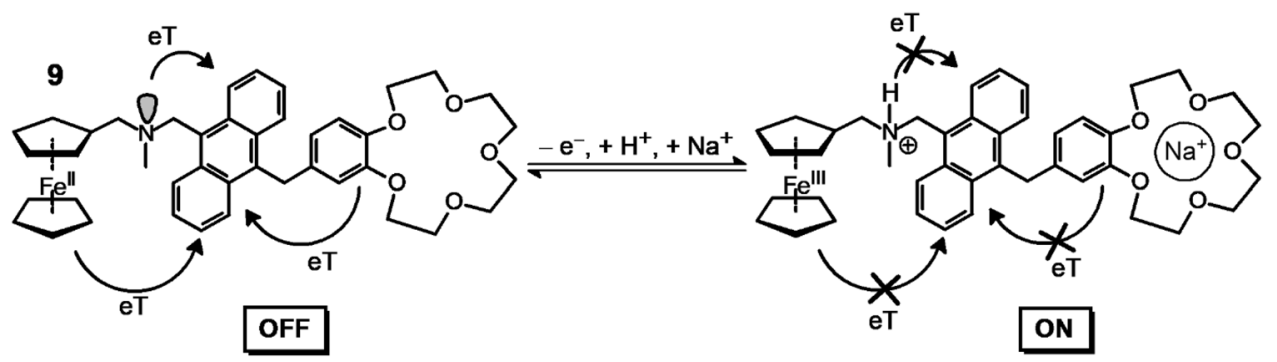

Fig. 10 A four-component switchable anthracene derivative (9) operated by 3 switches: (i) ferrocene; (ii) a tertiary amine group; (iii) a 1,2-dimethoxybenzene fragment. Each of the three subunits transfers independently one electron to the photo-excited anthracene fluoro-

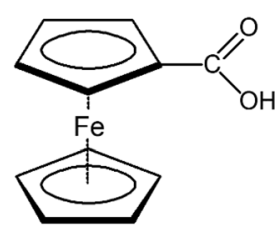

10

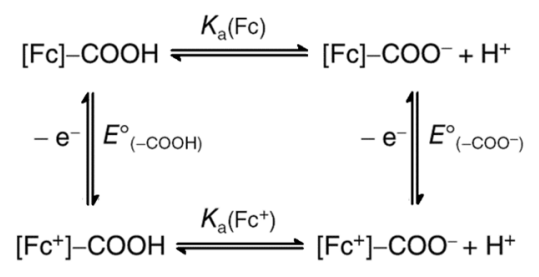

Fig. 11 Square scheme illustrating the acidic behaviour of the carboxylic acid 10 in its reduced $([\mathrm{Fc}]-\mathrm{COOH})$ and oxidised $\left(\left[\mathrm{Fc}^{+}\right]-\mathrm{COOH}\right)$ forms [35]

indicated by the calculated solid line in Fig. 12b. Moreover, $E_{1 / 2}$ values of the lower plateau $(\mathrm{pH} \geq 9)$ should correspond to $E^{\circ}\left(-\mathrm{COO}^{-}\right)=337 \mathrm{mV}$.

It has to be noticed that the increase of the positive charge of the organometallic substituent enhances substantially the acidity of the carboxylic group (by 1800 times). Such a behaviour may be reminiscent of that of classical oxoacids, whose ionisation constants increase by several $\log$ units on increasing the oxidation state of the central non-metal atom. On the other hand, on deprotonation of $-\mathrm{COOH}$, the $E^{\circ}$ value decreases by $200 \mathrm{mV}$, due to the delocalisation of the negative charge from $-\mathrm{COO}^{-}$onto the phore *An, quenching emission. Oxidation of $\mathrm{Fc}$ to $\mathrm{Fc}^{+}$, protonation of the amine group and coordination of $\mathrm{Na}^{+}$by the benzo-crownether prevents the occurrence of the three photo-induced eT processes, thus switching on the anthracene emission [34]

organometallic moiety and onto the metal centre, which makes the electron abstraction easier.

A similar titration experiment was carried out by adding standard $\mathrm{NaOH}$ to an $\mathrm{MeCN} / \mathrm{H}_{2} \mathrm{O}$ 4:1 solution of $\mathbf{1 0}$ made acidic with $\mathrm{HClO}_{4}$, and determining after each addition the DPV profile. This time the solution was unbuffered. In the distinctly acidic region $(\mathrm{pH}<4)$, a peak centred at $E_{1 / 2}=530 \mathrm{mV}$, corresponding to the reversible oxidation of the $\mathrm{Fc}-\mathrm{COOH}$ derivative, was observed. On further addition of base, the intensity of the peak centred at $E_{1 / 2}=530 \mathrm{mV}$ was observed to decrease, whereas a new symmetric peak developed at $E_{1 / 2}=335 \mathrm{mV}$ (see Fig. 13).

At $\mathrm{pH}>9$, the more anodic peak had completely disappeared and the peak at $335 \mathrm{mV}$ had reached a constant and limiting value. Such a peak should correspond to the oxidation of the $\mathrm{Fc}-\mathrm{COO}^{-}$species.

It should be noted that this type of voltammetric response is completely different from that observed in the experiments in which the $\mathrm{pH}$ had been adjusted by a $0.1 \mathrm{M}$ buffer (Fig. 12). In a buffered solution, the oxidation process alters the composition of the equilibrium mixture and the species $\mathrm{Fc}-\mathrm{COOH}, \mathrm{Fc}-\mathrm{COO}^{-}$and $\mathrm{H}^{+}$species present in the thin layer of solution at the electrode surface react to restore the pristine equilibrium conditions, according
Fig. 12 a DPV profiles taken at a platinum electrode for an $\mathrm{MeCN} / \mathrm{H}_{2} \mathrm{O}$ solution $(4: 1, \mathrm{v} / \mathrm{v})$ of $\mathrm{Fc}-\mathrm{COOH}(\mathbf{1 0})$ at varying $\mathrm{pH}$. The solution was $0.1 \mathrm{M}$ in $\mathrm{Bu}_{4} \mathrm{NClO}_{4}, T=25^{\circ} \mathrm{C}$. On a $\mathrm{pH}$ increase, $E_{1 / 2}$ values shift toward less positive potentials; b plot of $E_{1 / 2}$ values (symbols) vs $\mathrm{pH}$. The $\mathrm{pH}$ was adjusted by using the following buffers: pyridine $+\mathrm{HClO}_{4} ; 2$,6-dimethylpyridine $+\mathrm{HClO}_{4}$; ethylenediamine $+\mathrm{HClO}_{4}$. The solid line was calculated on the basis of Eq. (2) [35]
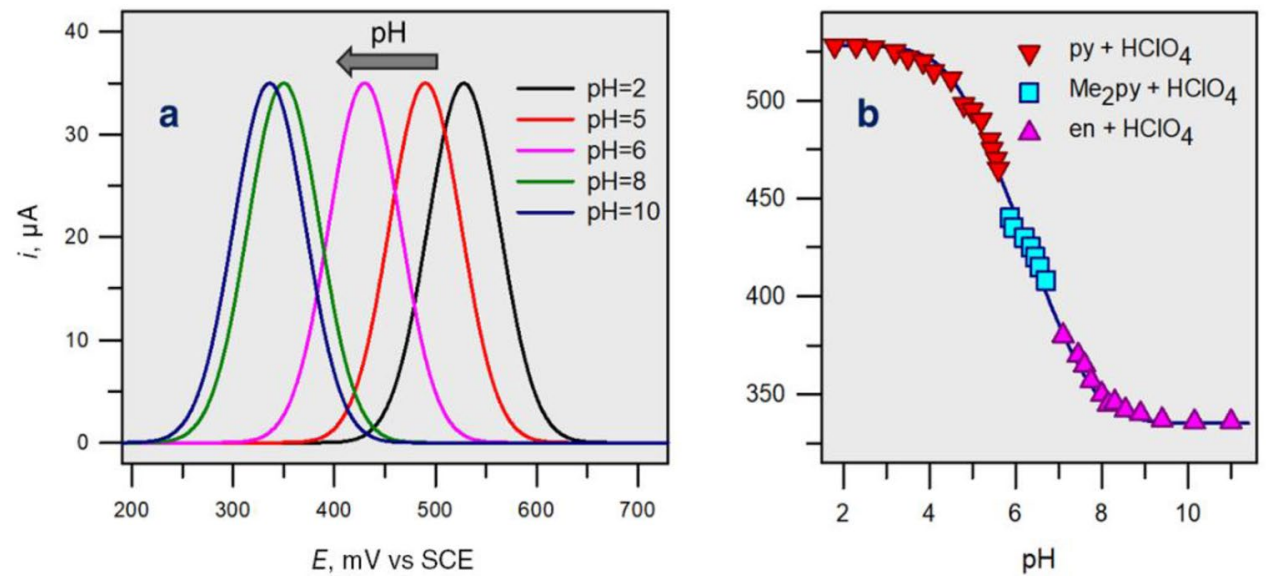


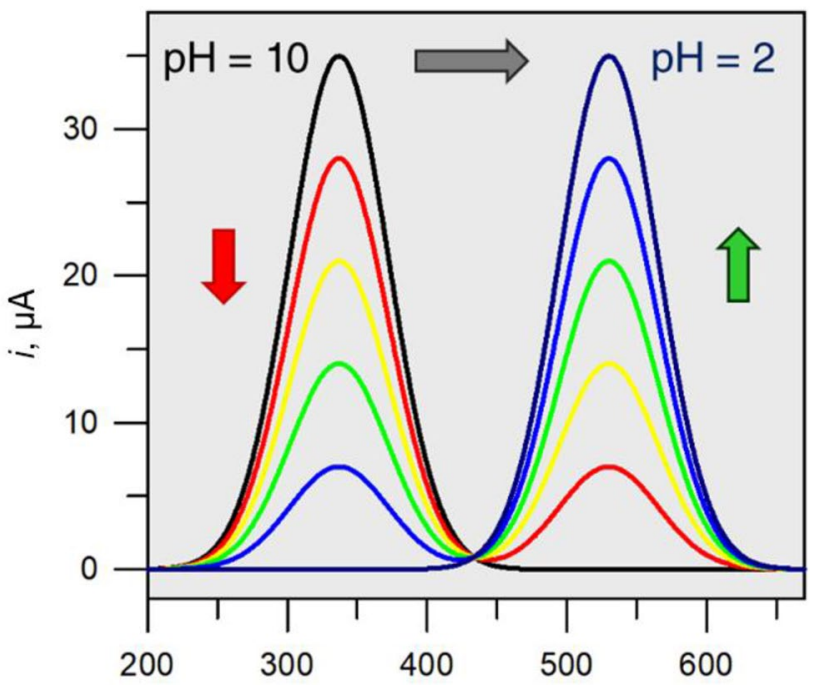

$E, \mathrm{mV}$ vs SCE

Fig. 13 DPV profiles for an unbuffered acidic solution of $\mathrm{Fc}-\mathrm{COOH}$ (10) on $\mathrm{pH}$ increase. Increasing the $\mathrm{pH}$ makes the peak at $530 \mathrm{mV}$ (black line, corresponding to the oxidation of the $\mathrm{Fc}-\mathrm{COOH}$ form) decrease and the peak at $335 \mathrm{mV}$ (oxidation of the $\mathrm{Fc}-\mathrm{COO}^{-}$form) increase; $\mathrm{pH}$ was varied through the addition of standard base to a solution of $\mathrm{Fc}-\mathrm{COOH}$ containing excess $\mathrm{HClO}_{4}$ [35]

to the square scheme in Fig. 11. Since the proton transfer is much faster than the heterogeneous electron transfer at the electrode, only a single peak is observed in the DPV profile, whose potential is determined by Eq. (2). On the contrary, in an unbuffered solution (Fig. 13), $\mathrm{H}^{+}$ions have to move from the bulk solution to reach the surface layer. Such a migration process is slower than the electron transfer at the electrode. Under these non-equilibrium conditions, on scanning the potential of the working electrode, first the oxidation of $\mathrm{Fc}-\mathrm{COO}^{-}$takes place, giving rise to its individual peak (at $335 \mathrm{mV}$ ). Then, at a more positive potential $(530 \mathrm{mV})$, well before that the thermodynamic equilibrium is restored, the intact $\mathrm{Fc}-\mathrm{COOH}$ species undergoes oxidation. The potential of the limiting cathodic peak corresponds to $E^{\circ}\left(\mathrm{Fc}-\mathrm{COO}^{-}\right)$and that of the limiting anodic peak to $E^{\circ}(\mathrm{Fc}-\mathrm{COOH})$. Moreover, the intensity of each peak should be proportional to the concentration of the corresponding redox active species.

From the scheme in Fig. 11, the following equation can be derived:

$\Delta E^{\circ}=E^{\circ}(-\mathrm{COOH})-E^{\circ}\left(-\mathrm{COO}^{-}\right)=59.16 \log \frac{K_{\mathrm{a}}\left(\mathrm{Fc}^{+}\right)}{K_{\mathrm{a}}(\mathrm{Fc})}$

Equation (3) demonstrates that the higher the horizontal potential separation of the two limiting peaks in Fig. 13 (which corresponds to the vertical potential difference between the two plateaus in the sigmoidal profile in Fig. 12b), the higher the perturbation exerted by the redox change on the acidic properties of the linked subunit. DPV studies under the same conditions showed that, in the series of carboxylic acids $\mathrm{Fc}-\mathrm{COOH}, \mathrm{Fc}-\mathrm{CH}_{2}-\mathrm{COOH}$ and $\mathrm{Fc}-\left(\mathrm{CH}_{2}\right)_{2}-\mathrm{COOH}, \Delta E^{\circ}$ varies according to the sequence $200 \mathrm{mV}, 120 \mathrm{mV}$ and $80 \mathrm{mV}$. Such a behaviour reflects the decrease of through-space electrostatic effects as the distance between the metal centre and the $-\mathrm{COOH}$ group increases. Moreover, presence of $-\mathrm{CH}_{2}-$ spacers prevents the $\pi$-delocalisation effect operating in the $\mathrm{Fc}-\mathrm{COO}^{-}$anion.

\section{Ferrocene-based electrochemical sensors for cations}

Systems in which the redox switch is linked to an ion receptor play a special role in supramolecular chemistry. In particular, the oxidation state of the redox unit can favour or disfavour the interaction of the receptor with a given substrate. The key parameter in these studies is $\Delta E_{1 / 2}$, i.e. the difference of the $E_{1 / 2}$ potentials before and after the occurrence of the receptor-substrate association. This quantity may provide useful information on the selectivity of the receptor-substrate interaction. In this perspective, a redox unit-receptor system is defined as an electrochemical sensor. This means that attention is now centred on the recognition process and the redox-active moiety plays an ancillary yet still essential role, that of reporter or signalling unit of the event. Ferrocene, in view of its chemical stability, of its versatile functionalisation and of its electrochemical reversibility is the ideal redox unit for the design of electrochemical sensors. On uptake of a cation $\mathrm{M}^{+}$by the linked receptor, the oxidation of $\mathrm{Fc}$ to $\mathrm{Fc}^{+}$becomes more difficult because of the electrostatic repulsion exerted by the proximate positive charge of $\mathrm{M}^{+}$and $E_{1 / 2}$ is shifted to more positive potentials (anodically). On the contrary, on uptake of an anion $\mathrm{X}^{-}$, the attractive electrostatic interaction between $\mathrm{Fc}^{+}$ and $\mathrm{X}^{-}$favours oxidation and $E_{1 / 2}$ is shifted to less positive potential (cathodically). Figure 14 shows the DPV profiles expected for the interaction of a ferrocene-based electrochemical sensor with a metal ion $\mathrm{M}^{+}$(anodic shift of $E_{1 / 2}$ ) and with an anion $\mathrm{X}^{-}$(cathodic shift of $E_{1 / 2}$ ).

The first electrochemical sensors for cations were designed by inserting a ferrocene fragment in the skeleton of a given receptor whose selective binding properties toward a class of metal ions had been previously ascertained. This is the case for cryptands, macrobicyclic ligands introduced by Jean-Marie Lehn in 1969 [36]. Cryptands (e.g. 11, 12, 13, current name l.m.n-crypt, where $l, m$ and $n$ indicate the number of ethereal oxygen atoms present in the three strands linking the two pivot 


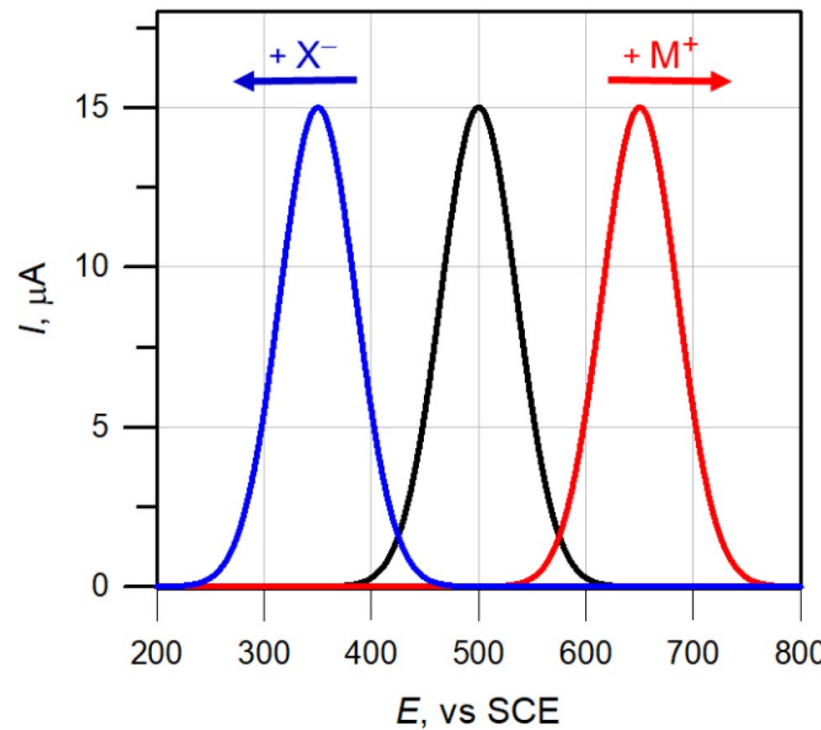

Fig. 14 Ideal DPV profiles for a ferrocene-based electrochemical sensor $\mathrm{Fc}-\mathrm{L}$. Following the interaction of the oxidised $\mathrm{Fc}^{+}-\mathrm{L}$ sensor with a cation $\mathrm{M}^{+}$, an anodic shift of $E_{1 / 2}$ is observed (red profile). The interaction of the oxidised sensor $\mathrm{Fc}^{+}-\mathrm{L}$ with an anion $\mathrm{X}^{-}$causes a cathodic shift (blue profile)

nitrogen atoms) form stable complexes with $s$ block metal ions in highly competing solvents, including water [37].

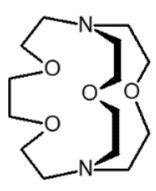

11

2.1.1-crypt

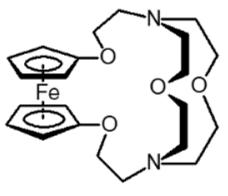

14

Fc-2.1.1-crypt

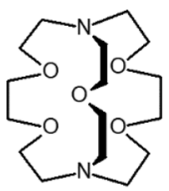

12

2.2.1-crypt

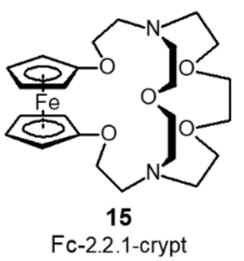

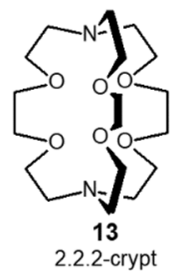

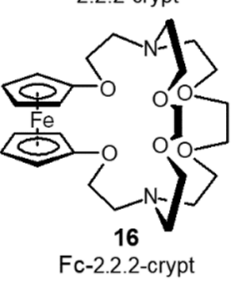

In particular, the cavity of the receptor can be modulated by varying the number of $\left(-\mathrm{CH}_{2}-\mathrm{CH}_{2}-\mathrm{O}-\right)$ fragments of each strand. Figure 15 shows the crystal structure of the $\left[\mathrm{K}(2.2 .2 \text {-crypt }]^{+}\right.$complex [38]. The alkali metal ion is well included in the cavity and profits from the coordination of all the donor atoms of the cryptand (4 oxygens and 2 nitrogens).

A remarkable property of cryptate complexes is that their stability depends upon the matching of the metal ion radius and the radius of the spheroidal cavity of the receptor [40]. Figure 16 a plots the $\log K$ values of the

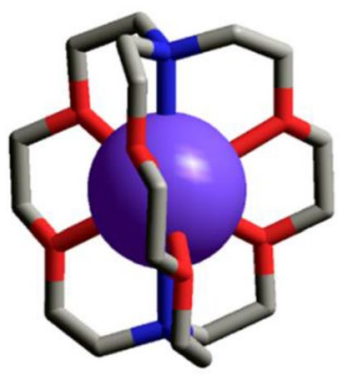

a

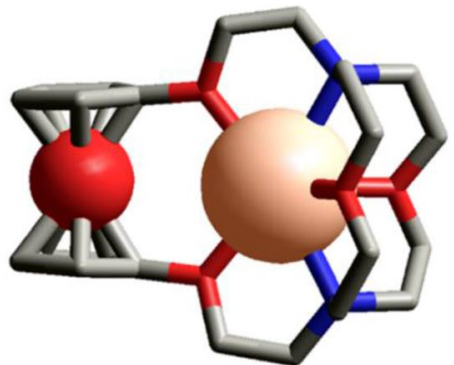

b
Fig. 15 a The crystal structure of the complex salt [ $\mathrm{K}(2.2 .2$-crypt $] \mathrm{I}$ [38]; hydrogen atoms and iodide have been omitted for clarity. b The crystal structure of the complex salt $\left[\mathrm{Ca}(\mathrm{Fc}-2.2 .2\right.$-crypt $]\left(\mathrm{ClO}_{4}\right)_{2}[39]$; hydrogen atoms and perchlorate ions have been omitted for clarity

complexation equilibria of alkali metal ions with cryptands of varying cavity size vs metal ion radii [41].

Figure 16a shows that each cryptand exhibits a defined selective affinity toward an alkali metal ion of a given radius. The smallest 2.1.1-crypt forms the most stable complex with the smallest alkali ion $\mathrm{Li}^{+}$. The medium size 2.2.1crypt forms the most stable complex with $\mathrm{Na}^{+}$, displaying a sharp peak selectivity. The cryptand of largest cavity size, 2.2.2-crypt shows a marked peak selectivity with the inclusion of $\mathrm{K}^{+}$. A significant contribution is also given by the number of oxygen atoms whose increase favours the complexation of metal ions of higher coordination number $\left(\mathrm{Li}^{+}<\mathrm{Na}^{+}<\mathrm{K}^{+}<\mathrm{Rb}^{+}<\mathrm{Cs}^{+}\right)$.

Cryptands with an integrated ferrocene moiety have been designed by replacing one of the three $-\mathrm{CH}_{2} \mathrm{CH}_{2}-$ chains linking two ethereal oxygen atoms with an $\mathrm{Fc}$ unit bound at the 1,1'-carbon atoms $(\mathbf{1 4}, \mathbf{1 5}, \mathbf{1 6} ; \mathrm{Fc}-$ l.m.n-crypt) [39]. Figure $15 \mathrm{~b}$ shows the crystal structure of the $[\mathrm{Ca}(\mathrm{Fc}-2.2 .2-$ crypt) $]^{2+}$ complex [39]. The $\mathrm{Ca}^{2+}$ ion is included in the cavity and is bound to all the six donor atoms. It is positioned at a $4.03 \AA$ distance from the iron centre and is expected to exert an electrostatic perturbation on the $\mathrm{Fc} / \mathrm{Fc}^{+}$oxidation process, a feature to be generally observed on complexation of $s$ block metal ions by ferrocene-cryptands. In fact, on formation of complexes of alkali metal ions with 14, 15 and 16, the $E_{1 / 2}\left(\mathrm{Fc}^{+} / \mathrm{Fc}\right)$ value undergoes an anodic shift varying from 100 to $400 \mathrm{mV}$. In Fig. 16b, the values of $\Delta E_{1 / 2}\left(=E_{1 / 2}\left(\mathrm{Fc}^{+} / \mathrm{Fc}\right)\right.$ complexed $-E_{1 / 2}\left(\mathrm{Fc}^{+} / \mathrm{Fc}\right)$ uncomplexed) for the three cryptands Fc-2.1.1-crypt, Fc-2.2.1crypt and Fc-2.2.2-crypt (MeCN, $25^{\circ} \mathrm{C}$ ) are plotted vs the ionic radius of alkali cations. The highest perturbing effects (ca. $400 \mathrm{mV}$ ) are observed on formation of [ $\mathrm{Li}(\mathrm{Fc}-2.2 .1$ crypt $)]^{+}$and $[\mathrm{Na}(\mathrm{Fc}-2.2 .1 \text {-crypt })]^{+}$complexes: it is probable that the smallest receptor brings the smallest alkali cations closest to iron. Complexation of all the alkali metal ions 

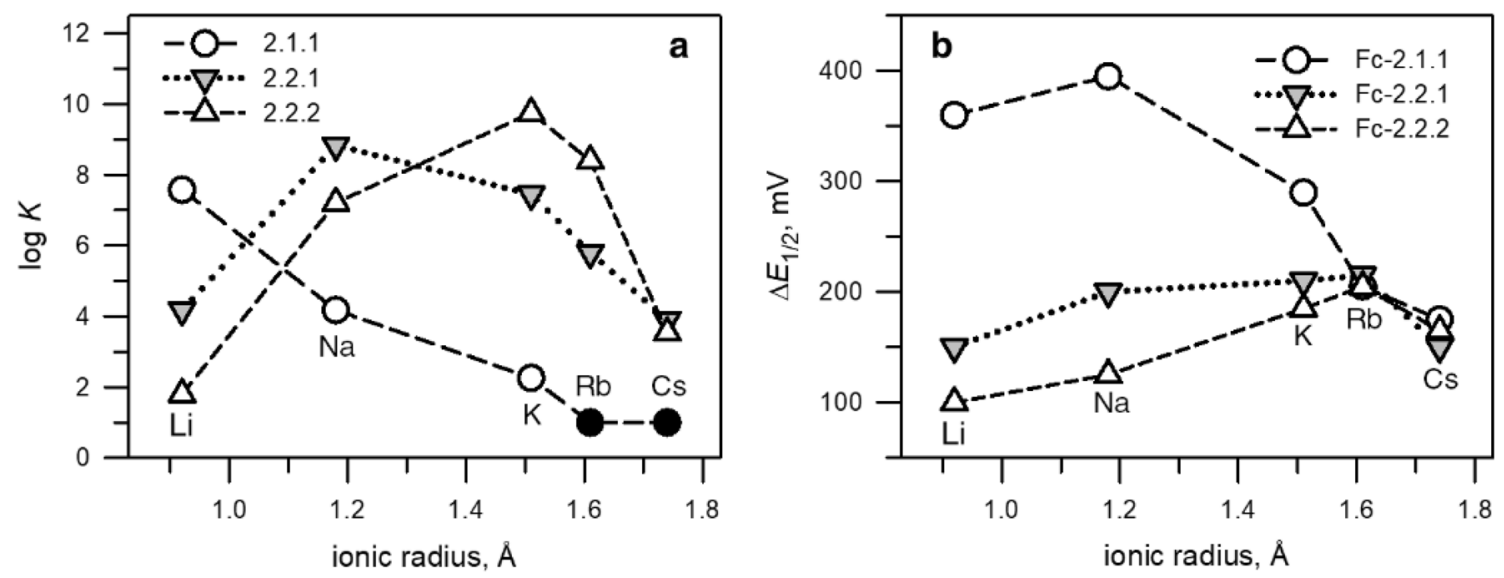

Fig. 16 a $\log K$ vs ionic radius for alkali metal complexes with cryptands 11, 12, 13 (MeOH/water 95:5) [41]; b $\Delta E_{1 / 2}$ vs ionic radius for complexation of alkali metal ions by ferrocene-cryptands 14, 15, 16 [39]
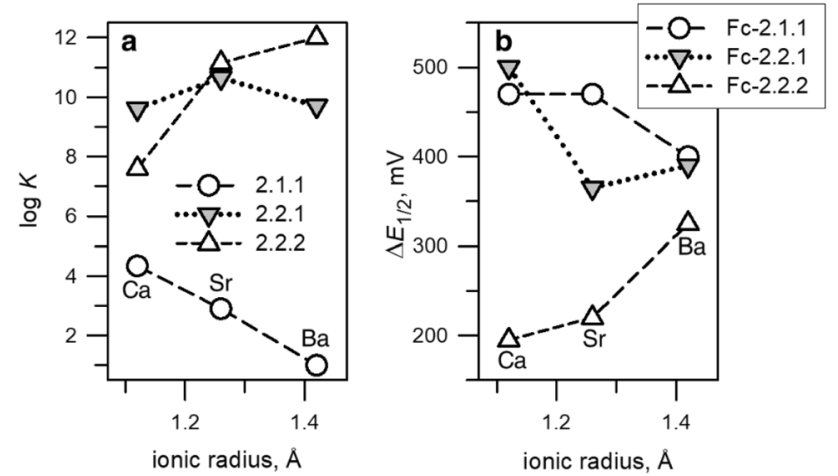

Fig. 17 a $\log K$ vs ionic radius for alkaline-earth metal complexes with cryptands 11, 12, $13\left(\mathrm{MeOH} /\right.$ water 95:5) [41]; b $\Delta E_{1 / 2}$ vs ionic radius for complexation of alkaline-earth metal ions by ferrocenecryptands 14, 15, 16 [39]

by $\mathrm{Fc}$-2.2.1-crypt and $\mathrm{Fc}-2.2 .2$-crypt generates less pronounced and non-selective $\Delta E_{1 / 2}$ values ranging from 100 to $200 \mathrm{mV}$.

Figure 17 a considers the solution stability of the alkaline-earth metal ions with the envisaged cryptands. In this case, too, $\log K$ values are related (1) to the match between the cation radius and the size of the receptor, and (2) to the number of donor oxygen atoms. In particular, $\mathrm{Ca}^{2+}$ is the preferred cation by 2.1.1-crypt, $\mathrm{Sr}^{2+}$ by 2.2.1-crypt (with a moderate selectivity peak), $\mathrm{Ba}^{2+}$ by 2.2.2-crypt [41].

Figure $17 \mathrm{~b}$ shows the $\Delta E_{1 / 2}$ values induced by coordination of the same alkaline-earth metal ion by ferrocene-cryptands 14, 15 and 16 [39]. A more pronounced perturbing effect is observed than for alkali metal ions, $\Delta E_{1 / 2}$ ranging from 200 to $500 \mathrm{mV}$, a consequence of the +2 electrical charge of the cation. For a given ferrocene

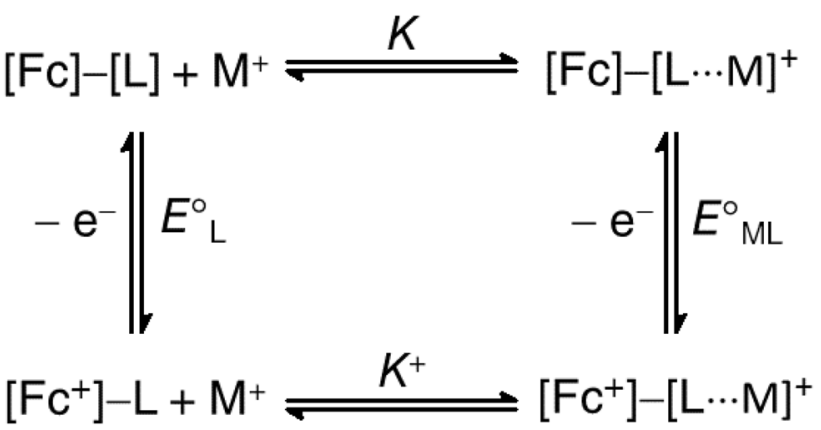

Fig. 18 Square scheme illustrating the complexation of an alkali metal ion $\mathrm{M}^{+}$by a ferrocene cryptand in its reduced, $[\mathrm{Fc}]-[\mathrm{L}]$, and oxidised, $\left[\mathrm{Fc}^{+}\right]-[\mathrm{L}]$, forms

cryptand, variations of $\Delta E_{1 / 2}$ as large as $250 \mathrm{mV}$ are observed $\left(\mathrm{Ca}^{2+} / \mathrm{Sr}^{2+}\right.$ for $\mathrm{Fc}-2.2 .1$-crypt; $\mathrm{Ca}^{2+} / \mathrm{Ba}^{2+}$ for Fc-2.2.2-crypt). However, a rationalisation seems difficult.

At this stage, in order to clarify the thermodynamic meaning of $\Delta E_{1 / 2}$, it is useful to consider the square scheme illustrated in Fig. 18. From such a scheme, the following equation can be derived:

$\Delta E_{1 / 2}=\Delta E^{\circ}=E_{\mathrm{ML}}^{\circ}-E_{\mathrm{L}}^{\circ}=59.16 \log \frac{K\left(\mathrm{Fc}^{+}\right)}{K(\mathrm{Fc})}$

Equation (4) demonstrates that $\Delta E_{1 / 2}$ is only dependent on the relative change in complexation constants between the different oxidation states. It follows that a large response is foreseeable in systems where the $\mathrm{Fc}-$ to- $-\mathrm{Fc}^{+}$oxidation process generates a species in which metal ion binding is strongly disfavoured and this happens when the receptor subunit forces the cation to place itself close to the redox centre. Therefore, in the case of electrochemical sensors of 
type 14-16, one should distinguish between selectivity, a property which depends upon the matching of the radii of the spherical cation and of the spheroidal receptor's cavity (expressed by the $\log K$ of the complexation of the reduced form) and sensitivity, a property which refers to the capability of the oxidised redox unit to exert electrostatic repulsive effects on the metal ion (expressed by $\Delta E_{1 / 2}$ ), thus giving a well-detectable electrochemical signal. Selectivity and sensitivity rarely coincide.

Electrochemical sensors have been designed by appending ferrocene subunits to polyamines, which display a pronounced affinity for $3 d$ metal ions. For instance, the ferrocene modified tetra-amine $\mathbf{1 7}(\mathrm{Fc}-\mathrm{tet})$ forms a stable square-planar complex with $\mathrm{Ni}^{\mathrm{iI}}(\log K=15.1$, determined through pH-metric titrations in aqueous $0.1 \mathrm{M} \mathrm{NaClO}_{4}$, $25^{\circ} \mathrm{C}$ ) [42]. The ferrocene fragment is oxidised at $361 \mathrm{mV}$ vs NHE in the uncomplexed Fc-tet and at $376 \mathrm{mV}$ in the $\left[\mathrm{Ni}^{\mathrm{II}}(\mathrm{Fc}-\mathrm{tet})\right]^{2+}$ complex. The very moderate $\Delta E_{1 / 2}(25 \mathrm{mV})$ reflects the fact that the metal ion is positioned at a relatively high distance from $\mathrm{Fc}$ and that electron density is transferred from amine nitrogen atoms to $\mathrm{Ni}^{\mathrm{II}}$, thus reducing its effective electrical charge [42].

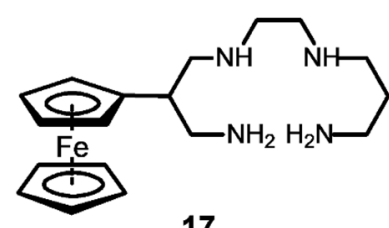

17

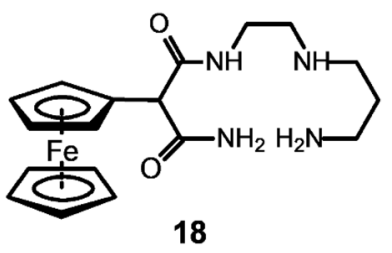

An unusual behaviour is displayed by the conjugate system 18, in which a ferrocene fragment is linked through a $\mathrm{C}-\mathrm{C}$ bond to the linear diamine-diamide ligand dioxo-tet [42]. Dioxo-tet exhibits scarce binding tendencies towards metal ions because it contains two poorly coordinating amide nitrogen atoms. However, dioxo-tet in slightly basic solutions and in the presence of a $3 d$ metal ion (e.g. $\mathrm{Ni}^{2+}$ or $\mathrm{Cu}^{2+}$ ) undergoes deprotonation of the two amide groups and forms a stable four-coordinate neutral complex. The process is described by equilibrium (i) in Fig. 19 (superior edge of the square scheme, which refers to Fc-dioxo-tet, 18).

It happens that oxidation of the $\mathrm{Fc}$ subunit of the metal complex, $\mathrm{Fc}-\left[\mathrm{Ni}^{\mathrm{II}} \mathrm{L}\right]^{0}$, takes place at a potential $\left(E_{1 / 2}=360 \mathrm{mV}\right)$ less positive than that of the uncomplexed system $\mathrm{Fc}-\mathrm{H}_{2} \mathrm{~L}\left(E_{1 / 2}=402 \mathrm{mV}\right)$. Thus, system 18 represents a unique example of a redox-functionalised ligand that on metal complexation features a negative, rather than a positive, $\Delta E_{1 / 2}(-58 \mathrm{mV})$. Such an unusual behaviour is due to the fact that $\mathrm{H}_{2} \mathrm{~L}$ on complexation releases the two amide protons and a double negative charge delocalises on the two $\mathrm{N}-\mathrm{C}-\mathrm{O}$ fragments. Such a negative charge on one side reduces the electrostatic repulsion exerted by $\mathrm{Ni}^{2+}$ and on the other side establishes an attractive interaction with the $\mathrm{Fc}^{+}$subunit.

\section{Ferrocene-based electrochemical sensors for anions}

An anion receptor typically binds the envisaged substrate through electrostatic interactions (when it contains in its skeleton positively charged groups, e.g. ammonium,

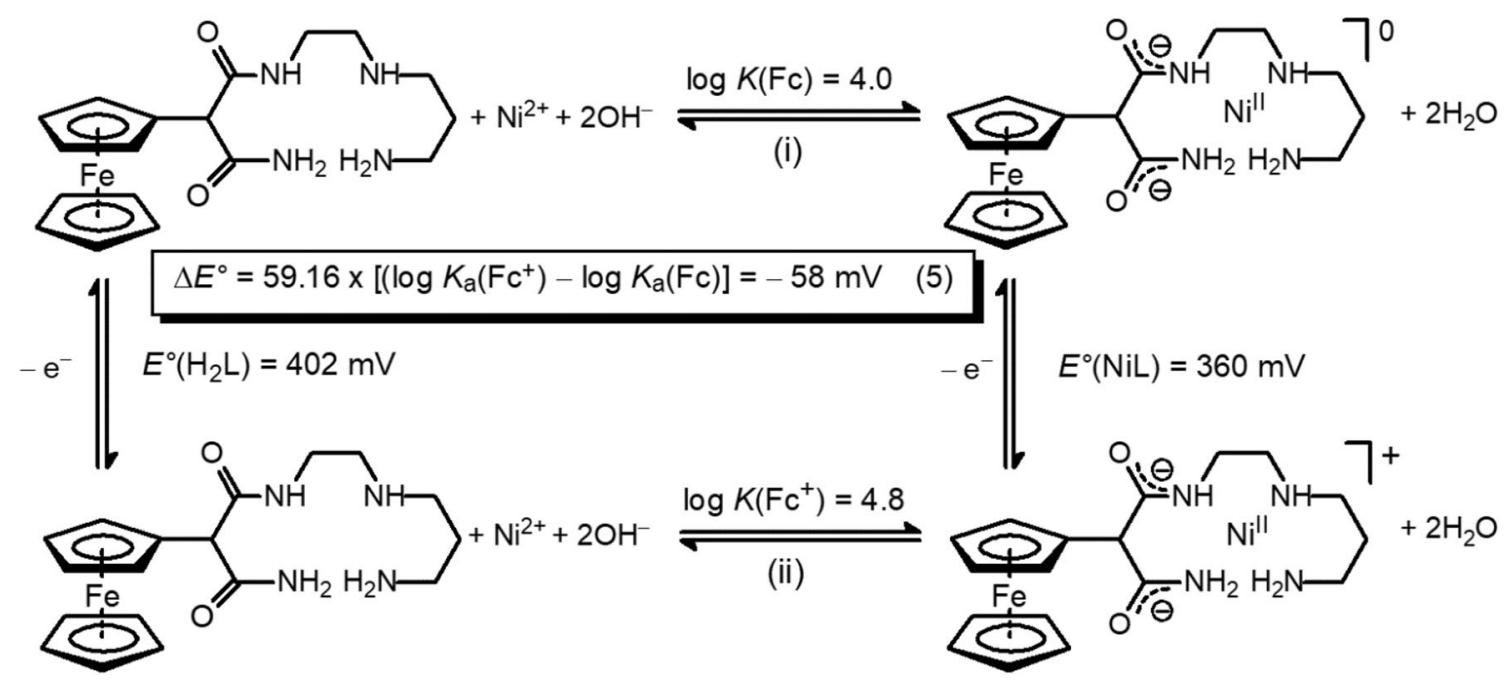

Fig. 19 Square scheme illustrating the reversible oxidation of Fcdioxo-tet $(\mathbf{1 8})$ in the absence and in the presence of complexed $\mathrm{Ni}^{\mathrm{II}}$. $K(\mathrm{Fc})$ of complexation equilibrium (i) has been independently deter- mined by $\mathrm{pH}$-metric titrations. Thus, $K\left(\mathrm{Fc}^{+}\right)$of equilibrium (ii) could be calculated from Eq. (4). All investigations were carried out in an aqueous solution of $0.1 \mathrm{M} \mathrm{NaClO}_{4}$ at $25{ }^{\circ} \mathrm{C}$ [42] 


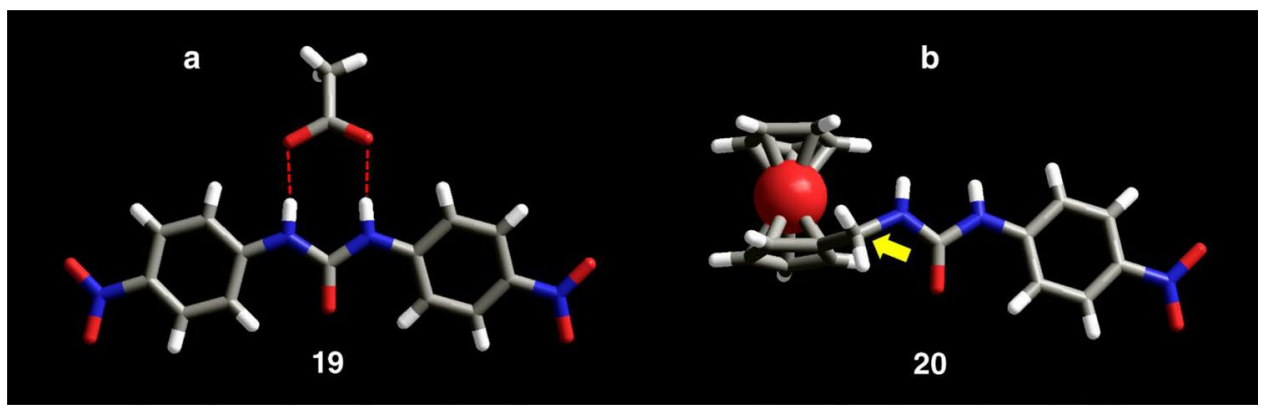

Fig. 20 a Crystal structure of the salt $\mathrm{Bu}_{4} \mathrm{~N}\left[\mathrm{~L} \cdots \mathrm{CH}_{3} \mathrm{COO}\right]$ ( $\mathrm{L}=\mathbf{1 9}=$ tetra- $n$-butylammonium 1,3-bis(4-nitrophenyl)urea); red dashed lines indicate the H-bonds donated by the urea $\mathrm{N}-\mathrm{H}$ frag-

guanidinium) and/or hydrogen bonding interactions (when it contains polarised $\mathrm{N}-\mathrm{H}$ fragments, e.g. from amides). Urea is a classical neutral receptor for anions capable of donating two convergent $\mathrm{H}$-bonds to a spherical anion (e.g. halide) or two 'parallel' H-bonds to two oxygen atoms of an oxoanion [43]. Figure 20a shows the crystal structure of the H-bond complex involving a urea derivative and an acetate ion [44].

Nitrophenyl substituents in $\mathbf{1 9}$ further polarise the amide $\mathrm{N}-\mathrm{H}$ fragments and enhance their $\mathrm{H}$-bond-donating tendencies. The complex is especially stable $(\log K=6.61$, in $\mathrm{MeCN}$ at $25{ }^{\circ} \mathrm{C}$ ), more than two orders of magnitude more stable than the corresponding complex of chloride ( $\log K=4.55$ under the same conditions). This is probably because the distance between the ureido nitrogen atoms is close to that between carboxylate oxygen atoms (2.28 and $2.14 \AA$, respectively), which allows the formation of almost collinear $\mathrm{N}-\mathrm{H}$... O hydrogen bonds, to be compared to the less intense bent $\mathrm{N}-\mathrm{H} \cdots \mathrm{Cl}$ bonds of the chloride complex [44].

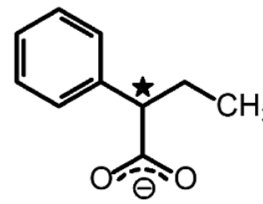

21

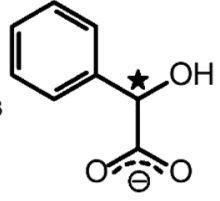

22

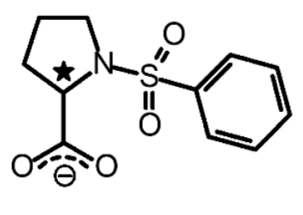

23
An electrochemical sensor for carboxylates has been synthesised by appending to the urea subunit a ferrocene moiety to give the electrochemical sensor 20, whose structure is displayed in Fig. 20b [45]. The interaction of $\mathbf{2 0}$ with a series of chiral carboxylates $(\mathbf{2 1}, \mathbf{2 2}, \mathbf{2 3})$ was investigated through voltammetric studies in $\mathrm{MeCN}$. In all cases, anion addition induced the expected cathodic shift of $E_{1 / 2}$. Just as an example, for 2-phenylbutyrate (21) a $\Delta E^{\circ}=81 \pm 1 \mathrm{mV}$ was determined, independently upon anion chirality, whether $R$ or $S$ : on the other hand, nobody would expect that an achiral receptor like $\mathbf{2 0}$ would 'recognise' ments to carboxylate oxygen atoms [44]; $\mathbf{b}$ the crystal structure of the electrochemical sensor for anion 20 ( $N$-(4-nitrophenyl)- $N$ '-(ferrocen1-ylmethyl)urea) [45] enantiomeric substrates. The chiral derivative 24, which had been obtained in its enantiomeric form $R$ by inserting a benzyl group at the carbon atom linked to the cyclopentadienyl ring of $\mathbf{2 0}$ (indicated in Fig. 20b by a yellow arrow) through a multistep synthetic procedure, was tested as an electrochemical sensor to discriminate the enantiomers of chiral carboxylates [45]. However, the voltammetric response was deceiving: $\Delta E^{\circ}$ values determined after the addition of the two enantiomers $S$ and $R$ of the anion of the 2-phenylbutyric acid (21) are nearly coincident: $\Delta E^{\circ}=82$ and $81 \mathrm{mV}$, respectively, the difference being lower than the experimental uncertainty. Similar results were obtained with the enantiomeric anions of mandelic acid (22), and the enantiomeric anions of the protected amino acid $N$-benzenesulfonyl proline (23). This does not necessarily mean that voltammetry is an inappropriate technique for identifying one enantiomer with respect to its mirror image. In fact, the $\log K$ values of the association equilibria of $\mathbf{2 4}$ with the $S$ and the $R$ form of mandelate (21) in DMSO, determined through spectrophotometric titration experiments, are 3.42 and 3.33, respectively, which means that their difference (0.09 log units) is in the range of the experimental error. Thus, failing of the enantiomeric discrimination has to be rather ascribed to the receptor's design, in particular to the positioning of the chiral centre too far for exerting selective steric interactions with the incoming anion.

Ferrocene derivatives have been designed that contain a subunit suitable for recognising an anion and an adjacent subunit capable to interact with cations. This is the case of system 25 in which two facing urea moieties provide a comfortable shelter for anions and two facing 18-crown-6 rings are eager to coordinate an alkaline metal ion [46]. In particular, system 25 can sense electrochemically the $\mathrm{KH}_{2} \mathrm{PO}_{4}$ salt in a DMSO solution (Fig. 21). However, in order to obtain significant voltammetric responses, a defined sequence of ion addition is required. In particular, on addition of $\mathrm{H}_{2} \mathrm{PO}_{4}{ }^{-}$to a solution of 25 , the peak of the $\mathrm{Fc} / \mathrm{Fc}^{+}$ couple (at $-310 \mathrm{mV}$, blue solid line in Fig. 22) undergoes a 


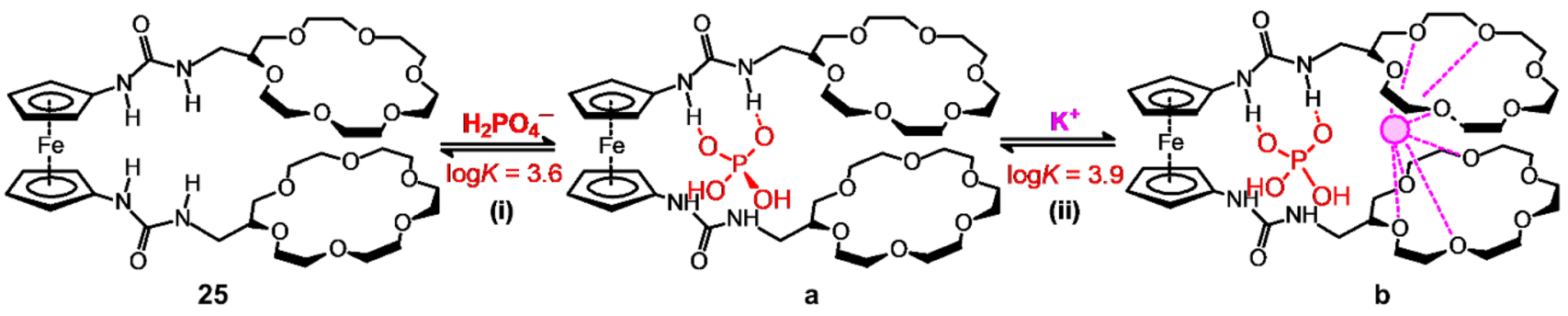

Fig. 21 A ferrocene derivative that senses anions and cations in sequence. The $\log K$ values refer to equilibria (i) $\mathrm{Fc}-\mathrm{L}+\mathrm{H}_{2} \mathrm{PO}_{4}{ }^{-} \rightleftarrows$ $\left[\mathrm{Fc}-\mathrm{L} \cdots \mathrm{H}_{2} \mathrm{PO}_{4}\right]^{-}$; (ii) $\left[\mathrm{Fc}-\mathrm{L} \cdots \mathrm{H}_{2} \mathrm{PO}_{4}\right]^{-}+\mathrm{K}^{+} \rightleftarrows\left[\mathrm{Fc}-\mathrm{L} \cdots \mathrm{H}_{2} \mathrm{PO}_{4} \cdots \mathrm{K}\right]$;

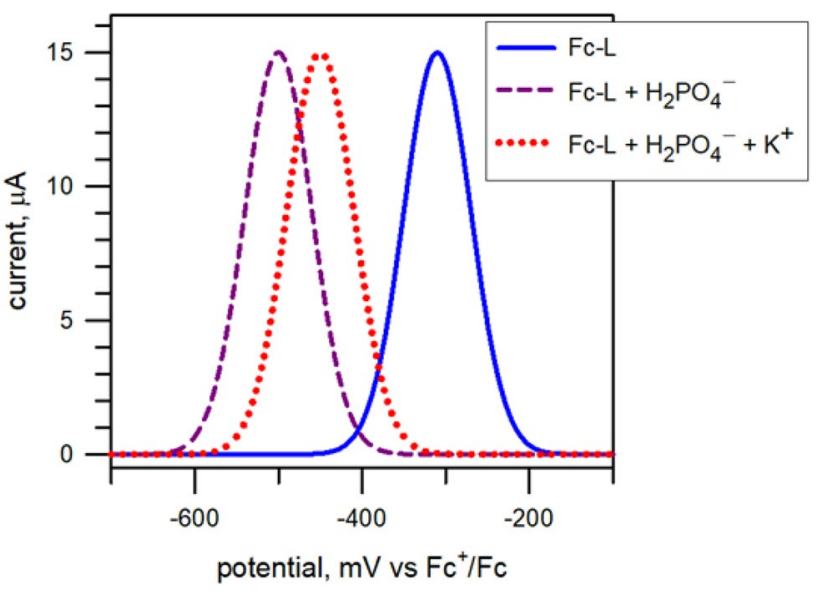

Fig. 22 DPV profiles for a solution of $\mathbf{2 5}$ in DMSO (blue solid line); a solution of $\mathbf{2 5}$ to which $\mathrm{H}_{2} \mathrm{PO}_{4}{ }^{-}$has been added (violet dashed line); the solution of $25+\mathrm{H}_{2} \mathrm{PO}_{4}{ }^{-}$to which $\mathrm{K}^{+}$has been added (red dotted line) [46]

significant cathodic shift $\left(\Delta E_{1 / 2}=-190 \mathrm{mV}\right.$; see the DPV profile-violet dashed line-in Fig. 22).

On the other hand, if $\mathrm{K}^{+}$is added to a solution of $\mathbf{2 5}$ the peak at $-310 \mathrm{mV}$ remains unaffected. Independent NMR titration experiments under the same conditions $\left(\mathbf{2 5}+\mathrm{K}^{+}\right)$demonstrated that $\mathrm{K}^{+}$interacts with the two crown-ether rings forming a stable complex. Thus, lack of electrochemical perturbation has to be ascribed to the fact that the complexed $\mathrm{K}^{+}$is too far from the ferrocene subunit to exert any electrostatic repulsion. However, if $\mathrm{K}^{+}$is added to a solution containing both 25 and $\mathrm{H}_{2} \mathrm{PO}_{4}^{-}$, the $\mathrm{Fc} / \mathrm{Fc}^{+}$peak undergoes an anodic shift $\left(\left(\Delta E_{1 / 2}=+50 \mathrm{mV}\right.\right.$; see the DPV profile-red dotted line-in Fig. 22). This is due to the fact that $\mathrm{H}_{2} \mathrm{PO}_{4}{ }^{-}$now interacts with the proximate $\mathrm{K}^{+}$ ion, a circumstance which reduces the charge available for the attractive electrostatic interaction with the ferrocenium subunit. This makes $\Delta E_{1 / 2}$ less negative by $50 \mathrm{mV}$.
$\mathrm{Fc}-\mathrm{L}=\mathbf{2 5}$. The $\log K$ values were determined through NMR titration experiments [46]

\section{Electron transfer across a liquid membrane mediated by the $\mathrm{Fc} / \mathrm{Fc}^{+}$redox couple}

A redox process is typically carried out by pouring the solution of the oxidising agent $(\mathrm{Ox})$ into the solution of the reducing agent (Red) (or vice versa) and the electron transfer proceeds through the intimate contact of the reactants. Alessandro Volta more than two centuries ago demonstrated that a redox process can be carried out by keeping the solution of Red and the solution of Ox separated and connected by a salt bridge. In such a device (or cell) electrons flow from Red to Ox through a metal wire, while cations and anions of the supporting electrolyte migrate through the salt bridge to maintain electroneutrality [47]. More recently it was shown that there is another way to carry out redox processes, still keeping the solutions of Red and Ox separated. Such a procedure requires a V-shaped vessel illustrated in Fig. 23.

In particular, the aqueous solution containing the reducing agent Red (a) is separated from the aqueous solution containing the oxidising agent $\mathrm{Ox}(\mathbf{b})$ by a layer of a water immiscible liquid (c, e.g. $\mathrm{CH}_{2} \mathrm{Cl}_{2}$ ). The interfacing liquid layer can be made permeable to electrons, thus becoming a membrane, by dissolving in it an appropriate molecular redox system $\mathrm{C}$, capable of undergoing a fast and kinetically uncomplicated one-electron redox change either $\mathrm{C} / \mathrm{C}^{+}$or $\mathrm{C} /$ $\mathrm{C}^{-}$. Among the available systems of type $\mathrm{C} / \mathrm{C}^{+}$, ferrocene is undoubtedly one of the strongest candidates. Thus, the electron transfer from Red to Ox can take place according to the mechanism illustrated in Fig. 24.

Ox diffuses to the interface with the membrane and there it oxidises $\mathrm{Fc}$ to $\mathrm{Fc}^{+}$. To maintain electroneutrality, $\mathrm{Fc}^{+}$uptakes an $\mathrm{X}^{-}$anion from the aqueous phase, to form the ion pair $\left[\mathrm{Fc}^{+}\right] \mathrm{X}^{-}$. The ion pair diffuses to the interface with the reducing phase, where it oxidises Red to $\operatorname{Red}^{+}$and releases $\mathrm{X}^{-}$. Fc is now ready for another cycle. In each cycle, one electron is transported from the reducing phase to the oxidising one, while one anion is counter-transported in the opposite direction. The $\mathrm{Fc} / \mathrm{Fc}^{+}$system operates in a cyclic way and needs to be present only in a catalytic amount. The 


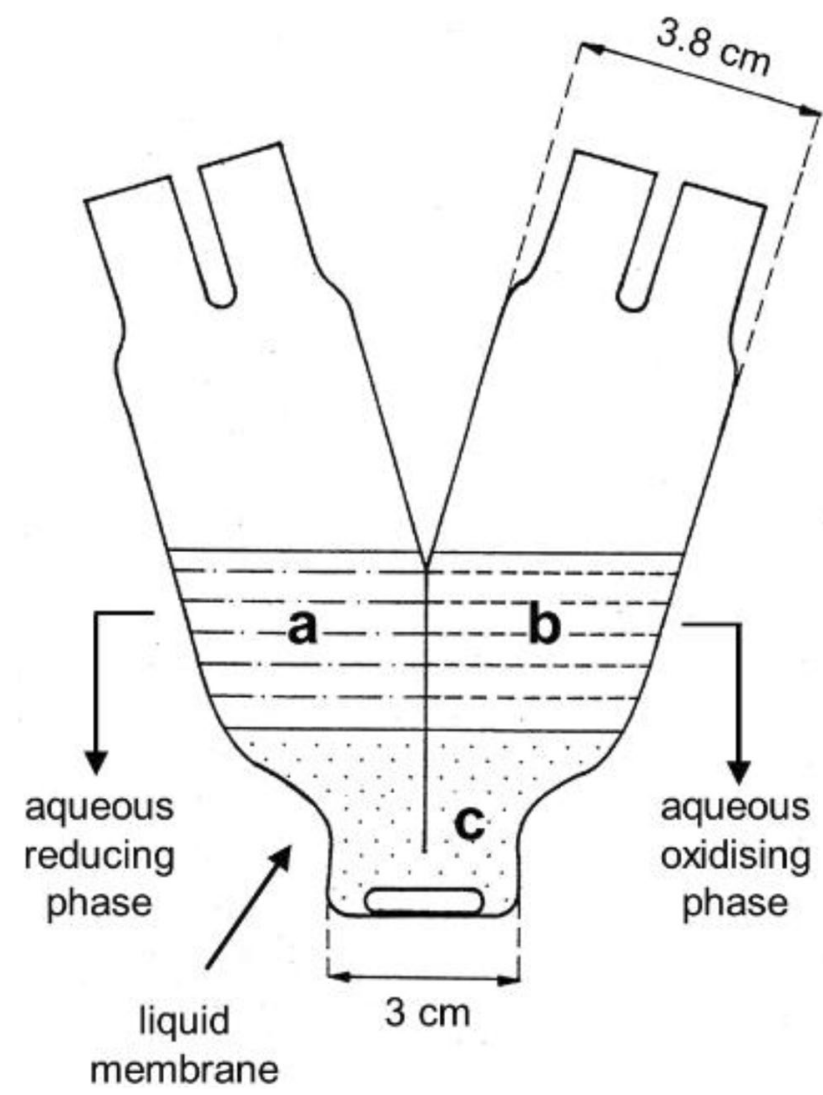

Fig. 23 V-shaped vessel used for carrying out oxidation and reduction reactions under three-phase conditions. The aqueous layer a containing the reducing agent and the aqueous layer $\mathbf{b}$ containing the oxidising agent are separated by a layer of a water immiscible liquid (c, e.g. $\mathrm{CH}_{2} \mathrm{Cl}_{2}$ ). A lipophilic redox system $\mathrm{C} / \mathrm{C}^{+}$dissolved in the organic layer (membrane) may allow electrons to move from $\mathbf{a}$ to $\mathbf{b}$. A magnetic stirrer on the bottom speeds the movement of $\mathrm{C}$ and $\mathrm{C}^{+}$by convection

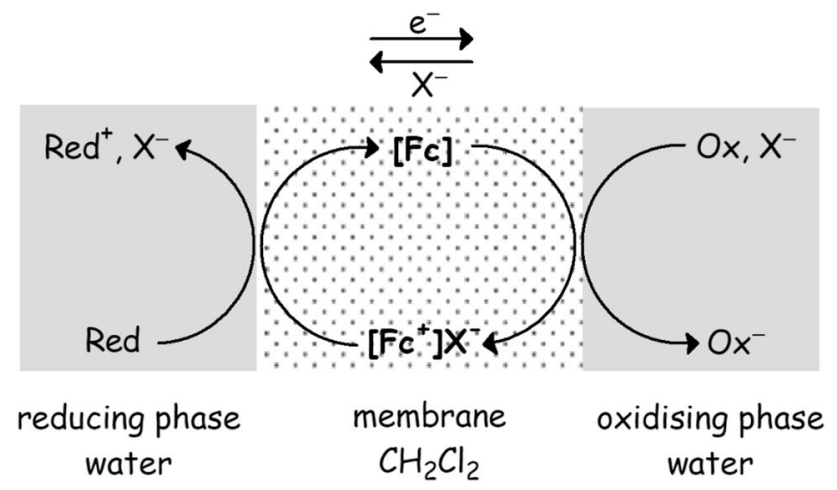

Fig. 24 Scheme illustrating the transport of electrons and the countertransport of anions $\mathrm{X}^{-}$across a liquid membrane, mediated by the $\mathrm{Fc} /$ $\mathrm{Fc}^{+}$redox system. $\mathrm{Fc}$ is the electron carrier, $\mathrm{Fc}^{+}$is the anion carrier

process goes on until the consumption of Ox or Red or, to be more precise, until the two aqueous layers have reached the same potential, exactly as it happens in a voltaic cell.
A strict prerequisite of the carrier is its complete insolubility in water, in both reduced and oxidised forms. Therefore, plain ferrocene cannot be used, as in its oxidised form it partitions between water and organic solvents. On the other hand, ferrocene derivatives with an appended long aliphatic chain $(\mathbf{2 6}, \mathbf{2 7})$ remain strictly confined in the liquid membrane and can act as efficient electron and anion carriers [48].

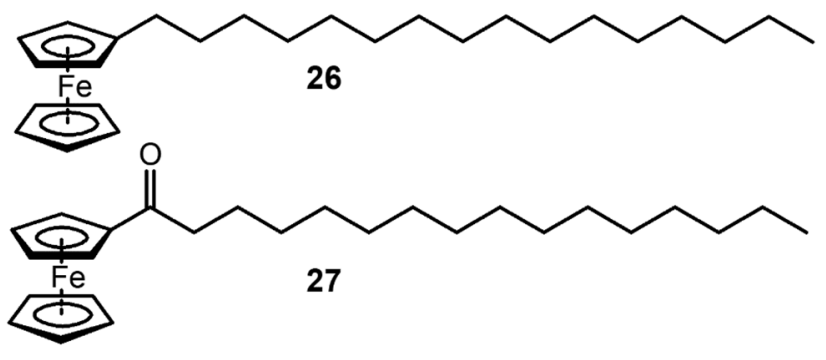

The ferrocene subunits in both derivatives undergo oneelectron oxidation at distinct potentials, as indicated by $\mathrm{CV}$ experiments in $\mathrm{CH}_{2} \mathrm{Cl}_{2} 0.1 \mathrm{M}^{\text {in }} \mathrm{Bu}_{4} \mathrm{NClO}_{4}$ : 26 at $-50 \mathrm{mV}$ vs plain ferrocene standard (moderate electron pumping effect by the aliphatic chain), 27 at $250 \mathrm{mV} \mathrm{vs} \mathrm{Fc}^{+} / \mathrm{Fc}$ (electron-withdrawing effect exerted by the proximate carbonyl group) [49]. Such a significant difference affords an interesting selectivity in electron transport experiments (vide infra).

When operating in a homogenous phase, e.g. water, one can predict the occurrence or not of a given redox process by looking at the electrochemical scale: the standard potential of the half-reaction of reduction involving the oxidising agent must be higher than the standard potential of the halfreaction of reduction involving the reducing agent. When operating under two-phase conditions (e.g. at the water/ $\mathrm{CH}_{2} \mathrm{Cl}_{2}$ interface) we have to juxtapose two distinct electrochemical scales and juxtaposition can be only empirical and tentative. In particular, it was preliminarily observed that on equilibrating (e.g. vigorously shaking) an aqueous layer containing $\mathrm{Ce}^{\mathrm{IV}}$ in strong acid $\left(E^{\circ}=1.61 \mathrm{~V}\right.$ vs NHE) with a $\mathrm{CH}_{2} \mathrm{Cl}_{2}$ layer containing either $\mathbf{2 6}$ or $\mathbf{2 7}$, the colour of the organic layer changes from orange $(\mathrm{Fc})$ to blue $\left(\mathrm{Fc}^{+}\right)$: the two-phase oxidation process takes place. On the other hand, the oxidised species, whether of $\mathbf{2 6}$ or of $\mathbf{2 7}$, is quantitatively reduced to the original ferrocene form by treatment, under two-phase conditions, with a mild aqueous reducing agent such as $\left[\mathrm{Fe}^{\mathrm{II}}(\mathrm{CN})_{6}\right]^{4-}\left(E^{\circ}=0.36 \mathrm{~V}\right.$ vs $\left.\mathrm{NHE}\right)$, as shown by the development of orange colour in the dichloromethane layer (and complete disappearance of the ferrocenium band at $628 \mathrm{~nm}$ ). These findings allowed one to adjust the relative positions of the electrochemical scales in water and in $\mathrm{CH}_{2} \mathrm{Cl}_{2}$ (see Fig. 25) [49].

In particular, the two scales should be juxtaposed in such a way that the potentials pertinent to the $\mathbf{2 6}^{+} / \mathbf{2 6}$ and the 


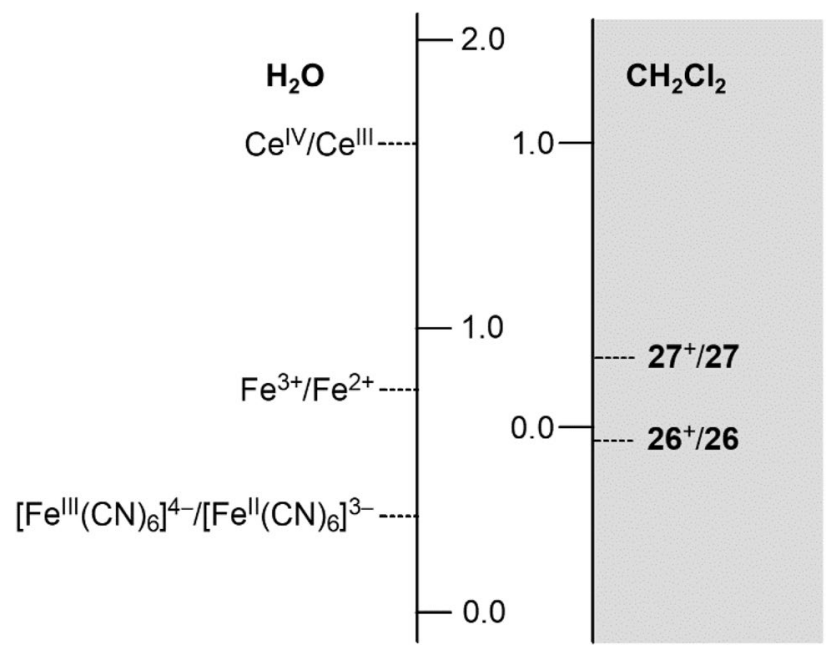

$(E, \mathrm{~V}$ vs $\mathrm{NHE}) \quad\left(E, \mathrm{~V}\right.$ vs $\left.\mathrm{Fc}^{+} / \mathrm{Fc}\right)$

Fig. 25 Electrochemical scales in water (standard potentials of reduction vs $\mathrm{NHE}$ ) and in $\mathrm{CH}_{2} \mathrm{Cl}_{2}$ (standard potentials of reduction vs $\mathrm{Fc}^{+}$/ $\mathrm{Fc}$ ). The two scales have been tentatively juxtaposed on the basis of two-phase water/ $\mathrm{CH}_{2} \mathrm{Cl}_{2}$ oxidation and reduction processes [49]

$27^{+} / 27$ couples are higher than that associated with the aqueous $\left[\mathrm{Fe}^{\mathrm{III}}(\mathrm{CN})_{6}\right]^{3-} /\left[\mathrm{Fe}^{\mathrm{II}}(\mathrm{CN})_{6}\right]^{4-}$ couple and lower than that associated with the aqueous $\mathrm{Ce}^{\mathrm{IV}} / \mathrm{Ce}^{\mathrm{III}}$ couple.

Selectivity effects induced by the nature of the ferrocene derivative are observed with two-phase experiments involving the aqueous $\mathrm{Fe}^{3+} / \mathrm{Fe}^{2+}$ couple. In fact, $\mathrm{Fe}^{3+}(1 \mathrm{M}$ $\mathrm{HClO}_{4}$ ) oxidises 26, under two-phase conditions, but not 27. On the other hand, $\mathrm{Fe}^{2+}\left(1 \mathrm{M} \mathrm{HClO}_{4}\right)$ reduces, under two-phase conditions, $\mathbf{2 7}^{+}$but not $\mathbf{2 6}^{+}$, as demonstrated by the colour changes and by spectral characterisation. All the aforementioned evidence indicates that the two electrochemical scales in water and $\mathrm{CH}_{2} \mathrm{Cl}_{2}$ should be juxtaposed as shown in Fig. 25. In particular, the potential associated with the aqueous $\mathrm{Fe}^{3+} / \mathrm{Fe}^{2+}$ couple $(0.77 \mathrm{~V}$ vs NHE) should be less positive than that of the $27^{+} / 27$ couple, but more positive than that of the $\mathbf{2 6}^{+} / \mathbf{2 6}$ couple. Such a situation opened the route to experiments of selective electron transport across liquid membranes.

In a typical experiment, the $\mathrm{V}$-shaped glass cell shown in Fig. 23 was charged with a dichloromethane solution (30 mL) $10^{-3} \mathrm{M}$ in 27. The $\mathrm{CH}_{2} \mathrm{Cl}_{2}$ layer (the membrane) separated the reducing phase $(30 \mathrm{~mL}$ of an aqueous solution $10^{-2} \mathrm{M}$ in $\left.\left[\mathrm{Fe}^{\mathrm{II}}(\mathrm{CN})_{6}\right]^{4-}\right)$ and the oxidising phase (30 mL of an aqueous solution $5 \times 10^{-2} \mathrm{M}$ in $\mathrm{Ce}^{\mathrm{IV}}$ and $1 \mathrm{M}$ in $\left.\mathrm{HClO}_{4}\right)$. After a few minutes, the originally orange liquid membrane took a blue colour, due to the formation of the ferrocenium derivative $\left(\mathbf{2 7}^{+}\right)$. The occurrence and progress of the electron transport was signalled by the appearance and the gradual increase in the concentration of $\left[\mathrm{Fe}^{\mathrm{III}}(\mathrm{CN})_{6}\right]^{3-}$ in the reducing phase, as monitored through the ferricyanide band at $420 \mathrm{~nm}$.

Figure 26a displays the variation of the concentration of $\left[\mathrm{Fe}^{\mathrm{III}}(\mathrm{CN})_{6}\right]^{3-}$ during the experiment, as calculated from spectra. According to the mechanism outlined in Fig. 24, $\mathrm{ClO}_{4}{ }^{-}$ions must be transported from the oxidising phase to the reducing phase, to guarantee electroneutrality. The concentration of perchlorate, $\left[\mathrm{ClO}_{4}{ }^{-}\right]$, was determined by extracting microportions of the aqueous reducing phase and carrying out appropriate analytical tests. The change of perchlorate concentration (\%) over time is shown in Fig. 26a. Noticeably, the plot of the increasing perchlorate concentration superimposes well, within the experimental error, with that of the ferricyanide concentration, which unequivocally demonstrates the simultaneous occurrence of the cross-transport of electrons and perchlorate anions and clearly defines its 1:1 stoichiometry. A similar behaviour was observed when using $\mathbf{2 6}$ as an electron carrier.
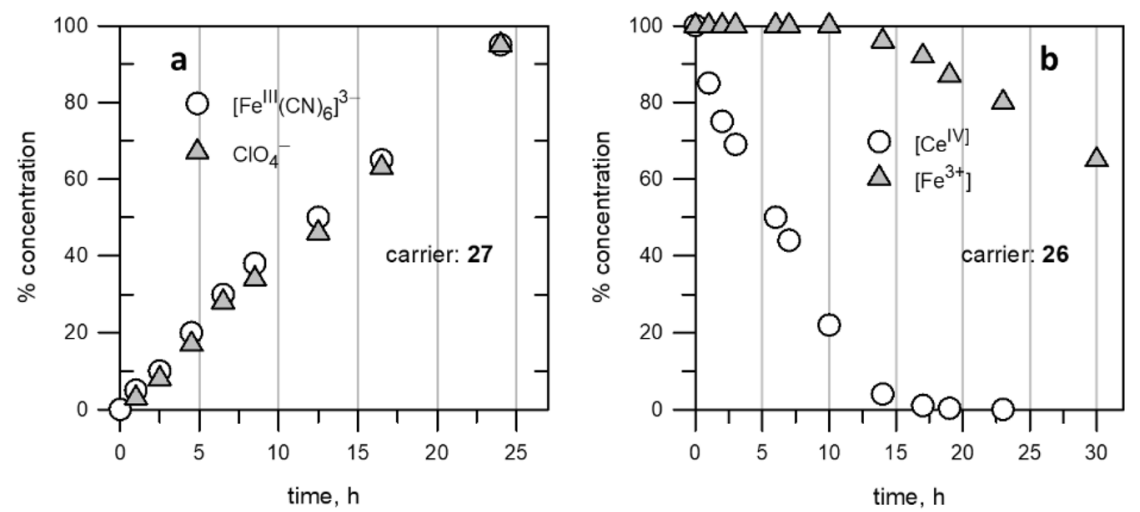

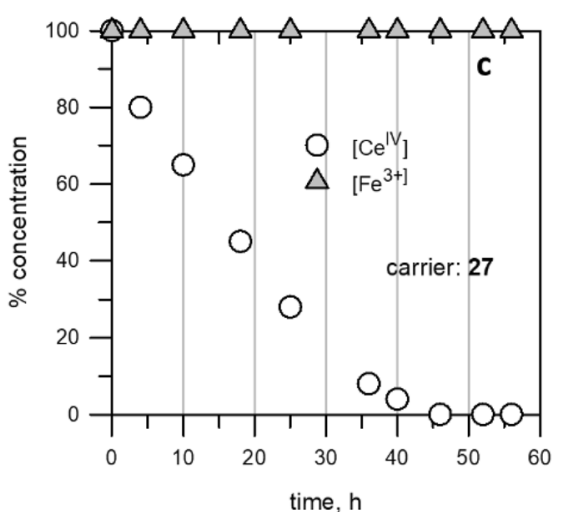

Fig. 26 a Cross-transport of electrons and $\mathrm{ClO}_{4}{ }^{-}$across a dichloromethane membrane, mediated by the electron carrier 27; aqueous reducing phase $(\mathrm{ARP}):\left[\mathrm{Fe}^{\mathrm{III}}(\mathrm{CN})_{6}\right]^{3-} 10^{-2} \mathrm{M}$; aqueous oxidising phase (AOP): $\mathrm{Ce}^{\mathrm{IV}} 5 \times 10^{-2} \mathrm{M}, \mathrm{HClO}_{4} 1 \mathrm{M}$; concentration profiles
(\%) of ferricyanide and perchlorate in ARP; b ARP: $\left[\mathrm{Fe}^{\mathrm{III}}(\mathrm{CN})_{6}\right]^{3-}$ $10^{-1} \mathrm{M}$; liquid membrane: $2610^{-3} \mathrm{M}$; AOP: $10^{-2} \mathrm{M}$ both in $\mathrm{Ce}^{\mathrm{IV}}$ and $\mathrm{Fe}^{3+}$ and $1 \mathrm{M}$ in $\mathrm{HClO}_{4}$; $\mathbf{c}$ the same as in $\mathbf{b}$, but with $2710^{-3} \mathrm{M}$ in the liquid membrane [49] 
Selectivity experiments were carried out by charging the reducing phase with $\left[\mathrm{Fe}^{\mathrm{II}}(\mathrm{CN})_{6}\right]^{4-} 10^{-1} \mathrm{M}$, the oxidising phase with both $\mathrm{Ce}^{\mathrm{IV}} 10^{-2} \mathrm{M}$ and $\mathrm{Fe}^{3+} 10^{-2} \mathrm{M}$, and $\mathrm{HClO}_{4}$ $1 \mathrm{M}$, while the membrane contained $2610^{-3} \mathrm{M}$. The progress of the electron/perchlorate cross-transport was followed by determining the concentration of the envisaged oxidising agent in extracted aliquots of the aqueous oxidising phase (spectrum of $\mathrm{Ce}^{\mathrm{IV}}$; spectrum of $\mathrm{Fe}^{3+}+2 \mathrm{M} \mathrm{NH}_{4} \mathrm{NCS}$ ). Figure 26b refers to the experiment in which $\mathbf{2 6}$ is present in the liquid membrane and shows the variation over time of the percentage concentration of the two oxidising agents, whose decrease is controlled by the Nernst equation: first, the concentration of the stronger oxidising agent, $\left[\mathrm{Ce}^{\mathrm{IV}}\right]$, decreases linearly, but, when it reaches a value of ca. $10 \%$, decreases with a less pronounced slope. At this point, the potentials of $\mathrm{Ce}^{\mathrm{IV}} / \mathrm{Ce}^{\mathrm{III}}$ and the $\mathrm{Fe}^{3+} / \mathrm{Fe}^{2+}$ potential should be nearly the same, and the decrease of $\left[\mathrm{Fe}^{3+}\right]$ begins. In particular, $\left[\mathrm{Fe}^{3+}\right]$ decreases linearly, but with a slope distinctly lower than $\left[\mathrm{Ce}^{\mathrm{IV}}\right]$. Nothing is known about the kinetics of the Fc-to-Ox electron transfer occurring in the boundary region of the water $/ \mathrm{CH}_{2} \mathrm{Cl}_{2}$ interface. However, it seems reasonable to assume that the crucial step involves the intimate contact of the two reagents and that the electron is transferred through an outer-sphere mode (imposed by the nature of the ferrocene carrier). In this situation, a Marcus-type cross relationship should hold $\left(k_{12}=\left\{k_{11} k_{22} K_{12}\right\}^{1 / 2}\right)$. On this basis, the rate constant of the two-phase redox process $k_{12}$ should increase (1) with increasing $\Delta E^{\circ}\left(=E^{\circ}(\mathrm{Ox} / \mathrm{Red})-E^{\circ}\left(\mathrm{Fc}^{+} /\right.\right.$ $\left.\mathrm{Fc}))=(R T / F) \ln K_{12}\right)$ and (2) with the self-exchange constant $k_{11}$ pertinent to the aqueous oxidising agent. Whereas the self-exchange constants are similar $\left[k_{11}=10^{4.4}\left(\mathrm{Ce}^{\mathrm{IV}}\right), 10^{4.0}\right.$ $\left.\left(\mathrm{Fe}^{3+}\right)\right]$, the remarkably higher value of $\Delta E^{\circ}$ should favour significantly the rate of the process involving $\mathrm{Ce}^{\mathrm{IV}}$, compared to $\mathrm{Fe}^{3+}$

Things go differently in the transport experiment mediated by carrier 27 and described by Fig. $26 \mathrm{c}$. [ $\left.\mathrm{Ce}^{\mathrm{IV}}\right]$ decreases linearly, but with a slope much lower than that observed with carrier 26 (Fig. 26b). The lower rate of the heterogeneous $\mathrm{Ce}^{\mathrm{IV}} / 25$ electron transfer can be also in this case explained in terms of a Marcus cross relationship, $K_{12}\left(\Delta E^{\circ}\right)$ being distinctly smaller than for $\mathrm{Ce}^{\mathrm{IV}} / \mathbf{2 6}$. However, the most important point of the present experiment is that $\left[\mathrm{Fe}^{3+}\right]$ remains at $100 \%$, even when $\mathrm{Ce}^{\mathrm{IV}}$ has been completely reduced. This is because $E^{\circ}\left(\mathrm{Fe}^{3+} / \mathrm{Fe}^{2+}\right)_{(\mathrm{aq})}$ lies below $E^{\circ}\left(\mathbf{2 7}^{+} / \mathbf{2 7}\right)_{(\mathrm{CH} 2 \mathrm{Cl} 2)}$ in the juxtaposed electrochemical scales in Fig. 25. Thus, the three-phase redox process appears selective. In particular, the redox-active liquid membrane acts as a filter that allows the passage only of electrons of higher energy than a chosen value (that determined by $E^{\circ}\left(\mathrm{C}^{+} / \mathrm{C}\right), \mathrm{C}=$ carrier $)$. Such a type of selectivity is not provided for instance by the voltaic cell, in which the oxidising agent takes electrons in sequence, through a metallic wire, from all the reducing agents present in the opposite cell.
This lecture text has covered aspects of the ferrocene/ ferrocenium redox change, which are close to the research interests and to the laboratory experience of the author and, in this sense, is rather selective. Further remarkable applications refer to molecular recognition and sensing by ferrocene-based polymers $[50,51]$ and the electrochemistry of ferrocene-functionalised surfaces $[52,53]$.

\section{Epilogue}

The versatile redox chemistry of $\mathrm{Fc}$, associated with the stability of the molecular framework and with the ease of functionalisation, has favoured the design of hundreds of ferrocene-based catalysts, including many efficient chiral ones, as well the application in materials science, nanomedicine, biological sensing and batteries. Moreover, ferrocene remains an icon of chemistry, which surprises the freshmen with its unusual shape, so different from classical organic and inorganic compounds they have encountered in the courses of chemistry at high school, and later it will help to convince students that molecular orbital theory represents the most convenient approach to describe molecules of varying complexity, including sandwich compounds. Ferrocene is often the first organometallic compound synthesised in university preparative laboratories from $\mathrm{FeCl}_{2}$ and $\mathrm{Na}\left(\mathrm{C}_{5} \mathrm{H}_{5}\right)$ and again it surprises and captivates students because of its properties: stability, crystallinity, solubility in solvents of varying polarity. Finally, students in the laboratory will probably observe that on treatment with mild oxidising agents like $\mathrm{AgNO}_{3}$ and $\mathrm{FeCl}_{3}$, ferrocene solution changes from orange to blue, due to the formation of ferrocenium. In doing these experiments, students can share the emotions that Professor Woodward's students experienced back in 1952. Chemistry changes quickly in its technical aspect, but feelings and excitement of chemistry never change.

Funding Open access funding provided by Università degli Studi di Pavia within the CRUI-CARE Agreement.

Open Access This article is licensed under a Creative Commons Attribution 4.0 International License, which permits use, sharing, adaptation, distribution and reproduction in any medium or format, as long as you give appropriate credit to the original author(s) and the source, provide a link to the Creative Commons licence, and indicate if changes were made. The images or other third party material in this article are included in the article's Creative Commons licence, unless indicated otherwise in a credit line to the material. If material is not included in the article's Creative Commons licence and your intended use is not permitted by statutory regulation or exceeds the permitted use, you will need to obtain permission directly from the copyright holder. To view a copy of this licence, visit http://creativecommons.org/licenses/by/4.0/. 


\section{References}

1. Kealy TJ, Pauson PL (1951) A new type of organo-iron compound. Nature 168:1039-1040

2. Miller SA, Tebboth JA, Tremaine JF (1952) Dicyclopentadienyliron. J Chem Soc 1952:632-635

3. Wilkinson G, Rosenblum M, Whiting MC, Woodward RB (1952) The structure of iron bis-cyclopentadienyl. J Am Chem Soc 74:2125-2126

4. Dunitz JD, Orgel LE, Rich A (1956) The crystal structure of ferrocene. Acta Crystallogr 9:373-375

5. Woodward RB, Rosenblum M, Whiting MC (1952) A new aromatic system. J Am Chem Soc 74:3458-3459

6. Fischer EO, Pfab W (1952) Cyclopentadien-metallkomplexe, ein neuer Typ metallorganischer verbindungen (metal complexes of cyclopentadiene, a new type of metalorganic compounds). Z Naturforsch B 7:377-379 (in German)

7. Eiland PF, Pepinsky R (1952) X-ray examination of iron biscyclopentadienyl. J Am Chem Soc 74:4971

8. Dunitz JD, Orgel LE (1953) Bis-cyclopentadienyl iron: a molecular sandwich. Nature 171:121-122

9. Wilkinson G (1952) The preparation and some properties of ruthenocene and ruthenicinium salts. J Am Chem Soc 74:6146-6147

10. Wilkinson G (1952) The preparation and some properties of the cobalticinium salts. J Am Chem Soc 74:6148-6149

11. Page JA, Wilkinson G (1952) The polarographic chemistry of ferrocene, ruthenocene and the metal hydrocarbon ions. J Am Chem Soc 74:6149-6150

12. Rosenblum M, Woodward RB (1958) The structure and chemistry of ferrocene. III. Evidence pertaining to the ring rotational barrier. J Am Chem Soc 80:5443-5449

13. Woodward RB, Hoffmann R (1969) The conservation of orbital symmetry. Angew Chem Int Ed 8:781-932

14. Kuwana T, Bublitz DE, Hoh G (1960) Chronopotentiometric studies on the oxidation of ferrocene, ruthenocene, osmocene and some of their derivatives. J Am Chem Soc 82:5811-5817

15. Geiger WE (2007) Organometallic electrochemistry: origins, development, and future ranges in different solvent. Organometallics 26:5738-5765

16. Koepp H-M, Wendt H, Strehlow H (1960) Der vergleich der spannungsreihen in verschiedenen solventien II (comparison of potential series in different solvents. II) Zeitschrift für Elektrochemie. Phys Chem Chem Phys 64:483-491 (in German)

17. Gagné RR, Koval CA, Lisensky GC (1980) Ferrocene as an internal standard for electrochemical measurements. Inorg Chem 19:2854-2855

18. Fabbrizzi L, Poggi A (2020) unpublished results

19. Gritzner G, Kuta J (1984) Recommendations on reporting electrode potentials in non-aqueous solvents. Pure Appl Chem $56: 461-466$

20. Noviandri I, Brown KN, Fleming DS, Gulyas PT, Lay PA, Masters AF, Phillips L (1999) The decamethylferrocenium/decamethylferrocene redox couple: a superior redox standard to the ferrocenium/ ferrocene redox couple for studying solvent effects on thethermodynamics of electron transfer. J Phys Chem B 103:6713-6722

21. Freyberg DP, Robbins JL, Raymond KN, Smart JC (1979) Crystal and molecular structures of decamethylmanganocene and decamethylferrocene. Static Jahn-Teller distortion in a metallocene. J Am Chem Soc 101:892-897

22. Strem Chemicals. Bis(pentamethylcyclopentadienyl)iron, $99 \%$. https://www.strem.com/catalog/v/26-0400/32/iron_12126-50-0. Accessed 4 Jul 2020

23. Scholz F, Schroder U, Gulaboski R, Domenech-Carbo A (2014) Electrochemistry of immobilized particles and droplets, 2nd ed. Springer, Berlin
24. Gulaboski R, Mirčeski V, Scholz F (2002) An electrochemical method for determination of the standard Gibbs energy of anion transfer between water and n-octanol. Electrochem Commun $4: 277-283$

25. Scholz F, Gulaboski R (2005) Determining the Gibbs energy of ion transfer across water-organic liquid interfaces with three-phase electrodes. Chem Phys Chem 6:1-13

26. Scholz F, Komorsky-Lovrić Š, Lovrić M (2002) A new access to Gibbs energies of transfer of ions across liquid/liquid interfaces and a new method to study electrochemical processes at welldefined three-phase junctions. Elctrochem Commun 2:112-118

27. Malischewski M, Seppelt K, Sutter J, Heinemann FW, Dittrich B, Meyer K (2017) Protonation of ferrocene: a low-temperature X-ray diffraction study of $\left[\mathrm{Cp}_{2} \mathrm{FeH}\right]\left(\mathrm{PF}_{6}\right)$ reveals an iron-bound hydrido ligand. Angew Chem Int Ed 56:13372-13376

28. Fabbrizzi L, Poggi A (1995) Sensors and switches from supramolecular chemistry. Chem Soc Rev 24:197-202

29. De Santis G, Fabbrizzi L, Licchelli M, Mangano C, Sacchi D (1995) Redox switching of anthracene fluorescence through the $\mathrm{Cu}^{\mathrm{II}} / \mathrm{Cu}^{\mathrm{I}}$ couple. Inorg Chem 34:3581-3582

30. Martínez R, Ratera, I, Tárraga A, Molina P, Veciana J (2006) A simple and robust reversible redox-fluorescence molecular switch based on a 1,4-disubstituted azine with ferrocene and pyrene units. Chem Commun 2006:3809-3811

31. Farrugia TJ, Magri DC (2013) 'Pourbaix sensors': a new class of fluorescent $\mathrm{pE}-\mathrm{pH}$ molecular AND logic gates based on photoinduced electron transfer. New J Chem 37:148-151

32. de Silva AP, Gunaratne HQN, McCoy CP (1993) A molecular photoionic AND gate based on fluorescent signalling. Nature 364:42-44

33. de Silva AP (2012) Molecular logic-based computation. RSC, Cambridge

34. Magri DC, Camilleri Fava M, Mallia CJ (2014) A sodium-enabled 'Pourbaix sensor': a three-input AND logic gate as a 'lab-ona-molecule' for monitoring $\mathrm{Na}^{+}, \mathrm{pH}$ and $\mathrm{pE}$. Chem Commun 50:1009-1011

35. De Santis G, Fabbrizzi L, Licchelli M, Pallavicini P (1994) Controlling the acidity of the carboxylic group by a ferrocene based redox switch. Inorg Chim Acta 225:239-244

36. Dietrich BB, Lehn J-M, Sauvage J-P (1969) Les cryptates. Tetrahedron Lett 10:2889-2892

37. Fabbrizzi L (2020) The origins of the coordination chemistry of alkali metal ions. ChemTexts 6:10

38. Moras D, Metz B, Weiss R (1973) Etude structurale des cryptates. I. Structure cristalline et moléculaire du 'cryptate de potassium', $\mathrm{C}_{18} \mathrm{H}_{36} \mathrm{~N}_{2} \mathrm{O}_{6}$. KI. Acta Cryst B29:383-388

39. Plenio H, Aberle C (1997) Oxaferrocene cryptands as efficient molecular switches for alkali and alkaline earth metal ions. Organometallics 16:5950-5957

40. Fabbrizzi L (2018) Cryptands and cryptates. World Scientific, London

41. Lehn J-M, Sauvage J-P (1975) [2]-Cryptates: stability and selectivity of alkali and alkaline-earth macrobicyclic complexes. J Am Chem Soc 97:6700-6707

42. De Santis G, Fabbrizzi L, Licchelli M, Pallavicini P, Perotti A (1992) A redox-switchable ligand for which the binding ability is enhanced by oxidation of its ferrocene unit. J Chem Soc Dalton Trans 1992:3283-3284

43. Amendola V, Fabbrizzi L, Mosca L (2010) Anion recognition by hydrogen bonding: urea-based receptors. Chem Soc Rev 39:3889-3915

44. Boiocchi M, Del Boca L, Esteban Gómez D, Fabbrizzi L, Licchelli M, Monzani E (2004) Nature of urea-fluoride interaction: incipient and definitive proton transfer. J Am Chem Soc 126:16507-16514 
45. Mulas A, Willener Y, Carr-Smith J, Joly KM, Male L, Moody CJ, Horswell SL, Nguyen HV, Tucker JHR (2015) The effect of central and planar chirality on the electrochemical and chiral sensing properties of ferrocenyl urea $\mathrm{H}$-bonding receptors. Dalton Trans 44:7268-7275

46. Otón F, Tárraga A, Velasco MD, Molina P (2005) A ferrocenebased heteroditopic ligand for electrochemical sensing of cations and anions. Dalton Trans 2005:1159-1161

47. Fabbrizzi L (2019) Strange case of Signor Volta and Mister Nicholson: how electrochemistry developed as a consequence of an editorial misconduct. Angew Chem Int Ed 58:5810-5822

48. De Santis G, Di Casa M, Fabbrizzi L, Licchelli M, Pallavicini $P$ (1991) Selective transport of anions across liquid membranes using the ferrocenium/ferrocene redox couple. Adv Mater 3:611-613

49. De Santis G, Fabbrizzi L, Licchelli M, Monichino A, Pallavicini P (1992) Ferrocene derivatives as electron carriers for selective oxidation and reduction reactions through a liquid membrane. $\mathbf{J}$ Chem Soc Dalton Trans 1992:2219-2224

50. Sun R, Wang L, Yu H, Abdin Z, Chen Y, Huang J, Tong R (2014) Molecular recognition and sensing based on ferrocene derivatives and ferrocene-based polymers. Organometallics 33:4560-4573
51. Saleem M, Yu H, Wang L, Abdin Z, Khalid M, Akram M, Nasir Abbasi M, Huang J (2015) Review on synthesis of ferrocenebased redox polymers and derivatives and their application in glucose sensing. Anal Chim Acta 876:9-25

52. Lee L, Downard AJ (2014) Preparation of ferrocene-terminated layers by direct reaction with glassy carbon: a comparison of methods. Solid State Electrochem 18:3369-3378

53. Nafady A, McAdam J, Bond AM, Moratti SC, Simpson J (2009) Electrochemical studies with dissolved and surface-confined forms of neo-pentyl-ferrocene-based polyesters utilising [ $\left.\mathrm{NBu}_{4}\right]$ $\left[\mathrm{B}\left(\mathrm{C}_{6} \mathrm{~F}_{5}\right)_{4}\right]$ and other electrolytes. J Solid State Electrochem 13:1511-1519

Publisher's Note Springer Nature remains neutral with regard to jurisdictional claims in published maps and institutional affiliations. 